\title{
WestVirginiaUniversity
}

THE RESEARCH REPOSITORY @ WVU

Graduate Theses, Dissertations, and Problem Reports

2000

\section{Spectroscopic investigations of new glass-ionomer dental cements}

Yigang Jin

West Virginia University

Follow this and additional works at: https://researchrepository.wvu.edu/etd

\section{Recommended Citation}

Jin, Yigang, "Spectroscopic investigations of new glass-ionomer dental cements" (2000). Graduate Theses, Dissertations, and Problem Reports. 1113.

https://researchrepository.wvu.edu/etd/1113

This Thesis is protected by copyright and/or related rights. It has been brought to you by the The Research Repository @ WVU with permission from the rights-holder(s). You are free to use this Thesis in any way that is permitted by the copyright and related rights legislation that applies to your use. For other uses you must obtain permission from the rights-holder(s) directly, unless additional rights are indicated by a Creative Commons license in the record and/ or on the work itself. This Thesis has been accepted for inclusion in WVU Graduate Theses, Dissertations, and Problem Reports collection by an authorized administrator of The Research Repository @ WVU. For more information, please contact researchrepository@mail.wvu.edu. 


\title{
SPECTROSCOPIC INVESTIGATIONS OF NEW GLASS-IONOMER DENTAL CEMENTS
}

\author{
Yigang Jin, B.S.
}

\author{
Thesis \\ Submitted to the \\ Eberly College of Arts and Science \\ at West Virginia University \\ in partial fulfillment of the requirement \\ for the Degree of \\ Master of Science \\ in \\ Chemistry
}

Paul W. Jagodzinski, Ph.D., Chair

Charles Jaffé, Ph.D.

Elizabeth C. Kao, D.M.D.

Björn C. Söderberg, Ph.D.

Department of Chemistry

Morgantown, West Virginia

2000

Keywords: Dental cement, Glass ionomer, Polyacid, Emission spectroscopy

Copyright 2000 Yigang Jin 


\section{ABSTRACT \\ Spectroscopic Investigations Of New Glass-Ionomer Dental Cements}

Yigang Jin, B.S.

Emission spectroscopy has been used to study conventional and resin modified glass-ionomer dental cements by monitoring the integrated peak intensities of signals arising from chromium ions in the aluminium oxide matrix as a function of reaction time.

Different conventional cements were prepared by mixing Fuji II glass with various polyacids. Emission spectra were collected and analyzed. The differences of the setting reactions (due to polysalt formation) were explained based on the concentration and availability of hydrogen ions from the polyacids with different structures.

Commercially available and experimental resin modified cements were prepared and emission spectra were collected to compare the different setting reactions (due to polysalt formation) with and without light irradiation. The differences of the polysalt formation were explained based on the formation of the polymer network due to the light-induced polymerization.

Fluorescence spectra of polyacids were also collected to explain the fluorescence interference in the emission spectra. 


\section{DEDICATION}

Idedic ate this Master of Science thesis to

my $f$ a mil y and a friend so important in my $l$ if e.

They al ways give me the greatest

support, encouragement, motivation, careand l ove.

Without them, Icould not fin ish this project.

THANK YOU

$\boldsymbol{\alpha}$

ILOVE YOU! 


\section{ACKNOWLEDGMENTS}

First of all, I'll have to thank Prof. Elizabeth C. Kao very much. Our collaboration is less than a year, but as a doctor and a researcher, her spirit and motivation give me the great impression. Her continuous patient instructions, help and encouragement are greatly appreciated, especially when I feel frustrated after failing an experiment. Also her enthusiasm makes me feel dentistry is so interesting.

Second, I would like to thank Prof. Charles Jaffé a lot. As one of the committee members, he greatly supports my project. His continuous help, constructive suggestions, instructions, patience and kindness in improving this thesis and on my study are generously appreciated.

Then, I must thank Prof. Björn C. Söderberg so much. At the very crucial moment, he becomes my committee member. Without his kind help I could not finish my thesis and defense. Also as my instructor, his knowledge, patient help, and his humorous instruction in class are really respectable and impressive.

I also need to thank Prof. Bill M. Culbertson at Ohio State University and Prof. Elizabeth C. Kao at Dentistry School of West 
Virginia University. They provided all the polymers used in this project and a lot of useful information.

I would also like to thank Michael B. Jacobs. Whenever in the lab or out of the lab, he gives me a lot of help. It is my pleasure to know him in America.

I also want to thank Zheng Ouyang, Chen Zuo, Ramaa Ramakrishnan and Gary Glaspell for supporting my experiments.

My final sincere appreciation goes to my advisor, Prof. Paul W. Jagodzinski. He's such a wonderful person that I respect, wherever in the academic field, in the work, or in life. I learned a lot from his hard working and great personality. His patient instructions, help, understanding, and trust in my study, in my work, and in my life are all especially appreciated. I can say it is really my luck and great pleasure to have him as my mentor in my early stages in America. I will never forget him, my boss, Tex. Thank you so much. 


\section{TABLE OF CONTENTS}

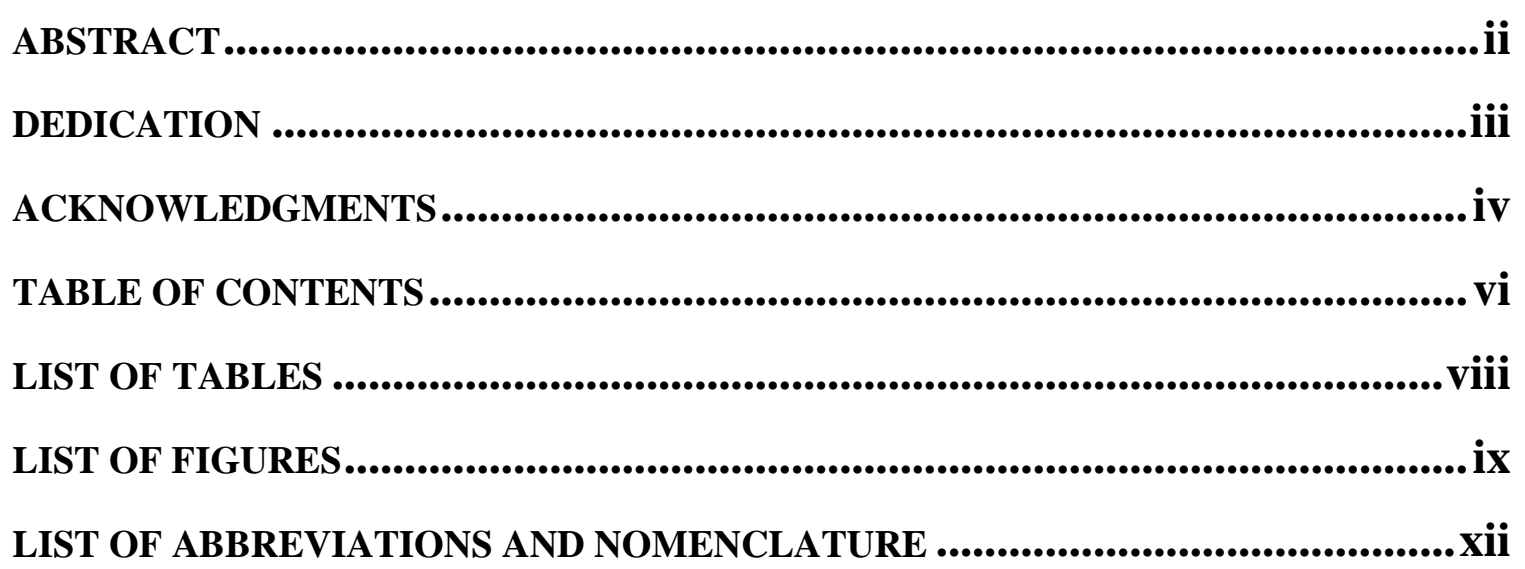

CHAPTER 1 - INTRODUCTION ......................................................... 1

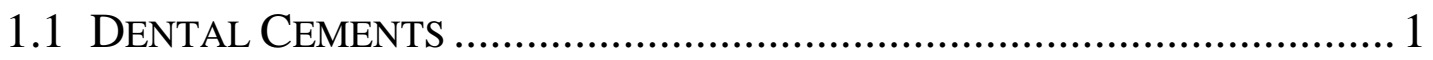

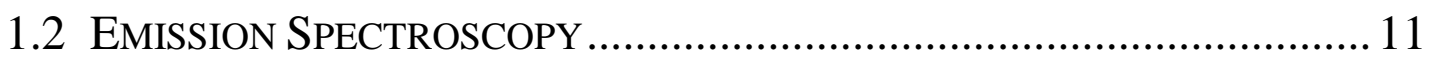

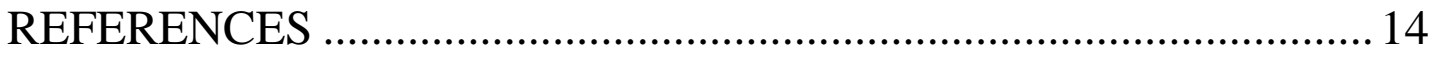

\section{CHAPTER 2 - SPECTROSCOPIC INVESTIGATIONS OF MODIFIED CONVENTIONALLY CURED GLASS-IONOMER DENTAL CEMENTS.....................16}

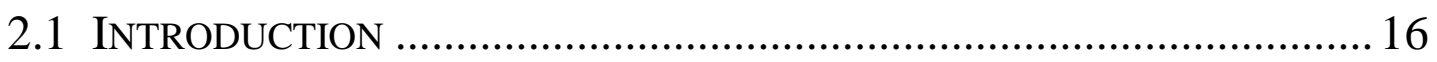

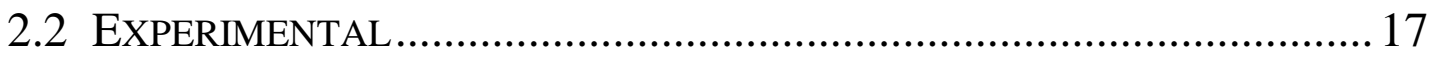

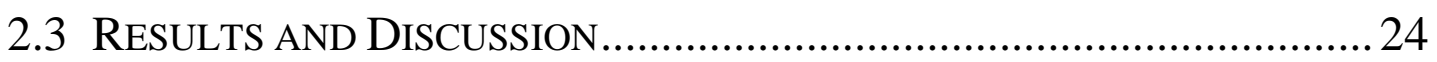

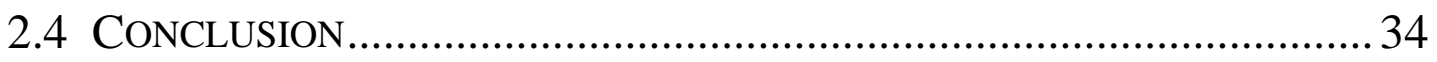

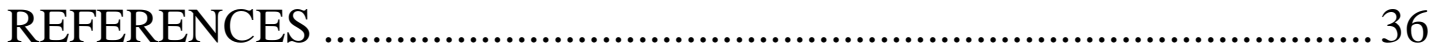




\section{CHAPTER 3 - SPECTROSCOPIC INVESTIGATIONS OF RESIN MODIFIED GLASS-IONOMER DENTAL CEMENTS ............................................................38}

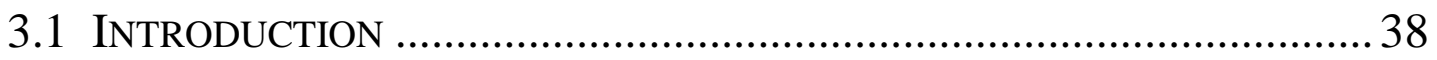

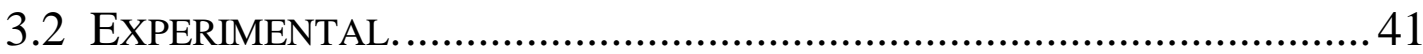

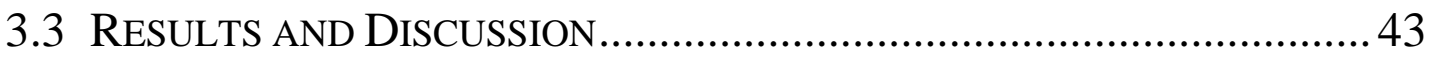

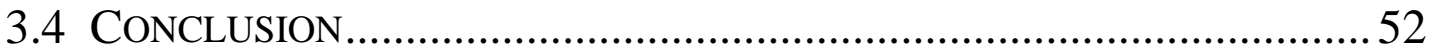

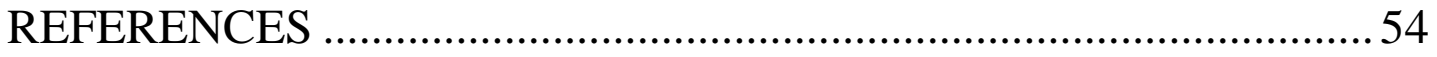

CHAPTER 4 - CONCLUSIONS .....................................................56

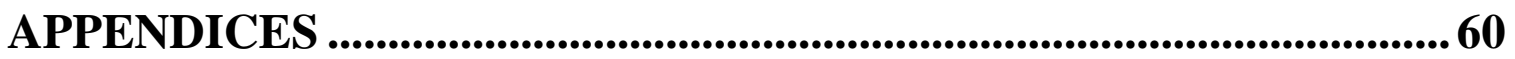

APPENDIX A. STRAND ERROR BARS FOR FIGURE 2-5

BY MicrosofT ${ }^{\circledR}$ EXCEL PROGRAM ............................... 61

APPENDIX B. STRAND ERROR BARS FOR FIGURE 3-1

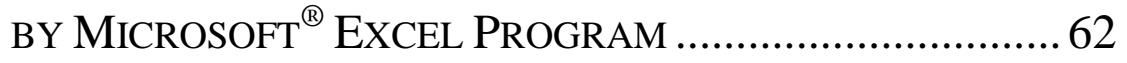

APPENDIX C. CONFIDENCE INTERVALS FOR TABLE 2-2

BY MicRosofT ${ }^{\circledR}$ EXCEL PROGRAM 


\section{LIST OF TABLES}

TABLE 1-1. COMPOSITIONS OF VARIOUS GLASS IONOMERS.................................... 2

TABLE 2-1. POLYACIDS USED IN THE STUDY ...................................................19

TABLE 2-2. pH VALUES, TIME OF COMPLETION OF SETTING REACTION, AND $\mathrm{AL}_{2} \mathrm{O}_{3}$ PERCENT OF COMPLETION OF SETTING REACTION OF VARIOUS POLYACIDS.......................................................................29

TABLE 3-1. COMPOSITIONS OF VITREMER RESIN GLASS IONOMER......................50 


\section{LIST OF FIGURES}

FIGURE 1-1. STRUCTURE OF CALCIUM ALUMINOSILICATE ......................................3

FigURE 1-2. SCHEMATIC STRUCTURES FOR POLYACID

HOMO- OR COPOLYMERS.......................................................................... 4

FIGURE 1-3. SCHEMATIC STRUCTURE OF IONIZATION OF POLYACID................... 4

FIGURE 1-4. REPRESENTATIVE REACTIONS IN THE FORMATION OF METAL POLYACRYLATE SALTS: A) -COO' ${ }^{-}$IONS REACT WITH $\left[\mathrm{CA}\left(\mathrm{H}_{2} \mathrm{O}\right)_{6}\right]^{2+}$ COMPLEX IONS; B ) - $\mathrm{COO}^{-}$IONS REACT WITH $\left[\mathrm{AL}\left(\mathrm{H}_{2} \mathrm{O}\right)_{6}\right]^{3+}$ COMPLEX IONS ALONG WITH F- IONS........................... 5

FIGURE 1-5. SCHEMATIC STRUCTURE OF FORMATION OF SILICA GEL ................. 6

FIGURE 1-6. OVERALL REACTION SCHEME OF GLASS-IONOMER CEMENTS........ 7

FIGURE 1-7. METAL TARTRATE COMPLEX ........................................................

FIGURE 1-8. DIAGRAM OF ELECTRONIC PROCESSES ........................................12

FIGURE 2-1. SCHEMATIC STRUCTURES FOR COPOL YMERS USED IN THIS STUDY. ...........................................18

FIGURE 2-2. EMISSION SPECTRUM OF INDENE .................................................22

FIGURE 2-3. EMISSION SPECTRA OF F2 C GLASS IONOMER AND AMN731 POLYACID DENTAL CEMENT AS A FUNCTION OF REACTION TIME. REFERENCE IS TO THE EXCITATION FREQUENCY $\left(15,453.56 \mathrm{CM}^{-1}\right)$ AT $0.0 \mathrm{CM}^{-1}$.....................................25 
FigURE 2-4. EMISSION SPECTRUM OF PURE $\mathrm{AL}_{2} \mathrm{O}_{3}$. REFERENCE IS TO THE EXCITATION FREQUENCY $\left(15,453.56 \mathrm{CM}^{-1}\right)$ AT $0.0 \mathrm{CM}^{-1} \ldots \ldots \ldots \ldots . . . . . .25$

Figure 2-5. TIME DEPENDENCE OF $\mathrm{AL}_{2} \mathrm{O}_{3}$ PERCENT IN F2 C GLASS IONOMER WHEN REACTED WITH VARIOUS POLYACIDS SHOWN IN LEGEND................................................... 27

FIGURE 2-6. FLUORESCENCE SPECTRA OF VARIOUS POLYACIDS.........................30

FigURE 2-7. FLUORESCENCE SPECTRA OF VARIOUS POLYACIDS IN 650 NM REGION. 31

FIGURE 2-8. EMISSION SPECTRUM OF NEAT POLYACID AIM811. REFERENCE IS TO THE EXCITATION FREQUENCY $\left(15,453.56 \mathrm{CM}^{-1}\right)$ AT $0.0 \mathrm{CM}^{-1}$ 33

FIGURE 2-9. EMISSION SPECTRUM OF NEAT POLYACID AIN821 BEFORE (A) AND AFTER (B) PURIFICATION. REFERENCE IS TO THE EXCITATION FREQUENCY $\left(15,453.56 \mathrm{CM}^{-1}\right)$ AT $0.0 \mathrm{CM}^{-1}$ 33

FiguRE 3-1. TIME DEPENDENCE OF $\mathrm{AL}_{2} \mathrm{O}_{3}$ PERCENT IN F2 LC GLASS-IONOMER DENTAL CEMENT WITH AND WITHOUT LIGHT-INDUCED POLYMERIZATION 45

FIGURE 3-2. MECHANISM OF LIGHT-INDUCED POLYMERIZATION AND SURFACE REACTION. 48

FIGURE 3-3. EMISSION SPECTRA OF VITREMER RM GLASS-IONOMER DENTAL CEMENT (A) AND ITS GLASS POWDER (B). REFERENCE IS TO THE EXCITATION FREQUENCY $\left(15,453.56 \mathrm{CM}^{-1}\right)$ AT $0.0 \mathrm{CM}^{-1}$ 49 
FiguRE 3-4. FLUORESCENCE SPECTRA OF F2 LC AND AIN713-IEM RM POLYACIDS (DOTTED LINES ARE FLUORESCENCE SPECTRA OF MODIFIED POLYACIDS) ...........................................551

FigURE 3-5. FLUORESCENCE SPECTRA OF F2 LC AND AIN713-IEM RM POLYACIDS IN 650 NM REGION (DOTTED LINES ARE FLUORESCENCE SPECTRA OF MODIFIED POLYACIDS) ......................51 


\section{LIST OF ABBREVIATIONS AND NOMENCLATURE}

AA

IA

MA

NVP

MGA

AMN731

AMN713

AIM811

AIN713

AIN821

HEMA

IEM

AIN713-IEM

RM

F2 C

F2 LC

$\mathrm{SiO}_{2}$

$\mathrm{Al}_{2} \mathrm{O}_{3}$

$\mathrm{CaF}_{2}$

$\mathrm{NaF}$

$\mathrm{Al}^{3+}$

$\mathrm{Ca}^{2+}$

$\mathrm{Na}^{+}$

$\mathrm{Cr}^{3+}$

$\mathbf{F}^{-}$

$-\mathrm{COOH}$

$-\mathrm{COO}^{-}$

$\mathbf{H}^{+}$
Acrylic Acid

Itaconic Acid

Maleic Acid

$N$-Vinylpyrrolidone

N-Methacrolylglutamic Acid

$A A: M A: N V P=7: 3: 1$

$A A: M A: N V P=7: 1: 3$

$A A: I A: M G A=8: 1: 1$

AA:IA:NVP=7:1:3

$A A: I A: N V P=8: 2: 1$

Hydroxyethylmethacrylate

2-Isocyanatoethylmethacrylate

AA:IA:NVP=7:1:3 grafted with 10\% IEM

Resin Modified

Fuji II Conventional Dental Cement

Fuji II Resin Modified Dental Cement

Silica or Silicic Anhydride

Alumina or Aluminium Oxide

Calcium Fluoride

Sodium Fluoride

Aluminium ion(s)

Calcium ion(s)

Sodium ion(s)

Chromium ions(s)

Fluoride ion(s)

Carboxyl group(s)

Carboxylate ion(s)

Hydrogen ion(s) 


\section{CHAPTER 1}

\section{INTRODUCTION}

It is well known that glass-ionomer cements ${ }^{[1-5]}$ were first developed by A. D. Wilson and B. E. Kent at the English Laboratory of the Government Chemist ${ }^{[6]}$ and have been widely used as clinically attractive dental restorative materials.

\subsection{DENTAL CEMENTS}

Glass-ionomer dental cements involve mixing calcium fluoroalumino-silicate glass powder and an aqueous solution of polyacid. The glass-ionomer powder composition is complex and varied. The original ionomer glass, G-200, and the recently commercially used glass ionomers, such as Fuji II glass ionomer used in this study, all contain silica (i.e. silicic anhydride, $\left.\mathrm{SiO}_{2}\right)$, aluminium oxide $\left(\mathrm{Al}_{2} \mathrm{O}_{3}\right)$, calcium fluoride $\left(\mathrm{CaF}_{2}\right)$, and a small amount of sodium fluoride $(\mathrm{NaF})$, with a few other components. ${ }^{[7-9]}$ The compositions of two representative glass-ionomer powders are shown in Table 1-1. The initially developed glass powder was a calcium 
aluminosilicate glass. The structure of calcium aluminosilicate ${ }^{[7]}$ in the glass powder is shown in Figure 1-1. The aluminum and silicon jointly share the oxygen atoms and the calcium $\left(\mathrm{Ca}^{2+}\right)$ and sodium $\left(\mathrm{Na}^{+}\right)$ions lie in the interstitial spaces. The most important polyacids used to date are acrylic acid homopolymers, acrylic acid and itaconic acid copolymers, and acrylic acid

i. Composition of the original ionomer glass, G-200 ${ }^{[8]}$

\begin{tabular}{|c|c|}
\hline Component & Composition (\%) \\
\hline $\mathrm{SiO}_{2}$ & 30.1 \\
\hline $\mathrm{Al}_{2} \mathrm{O}_{3}$ & 19.9 \\
\hline $\mathrm{AlF}_{3}$ & 2.6 \\
\hline $\mathrm{CaF}_{2}$ & 34.5 \\
\hline $\mathrm{NaF}$ & 3.7 \\
\hline $\mathrm{AlPO}_{4}$ & 10.0 \\
\hline
\end{tabular}

ii. Composition of Fuji II glass ionomer ${ }^{[9]}$

\begin{tabular}{|c|c|}
\hline Component & Composition (\%) \\
\hline $\mathrm{Al}_{2} \mathrm{O}_{3}$ & 21.0 \\
\hline $\mathrm{SiO}_{2}$ & 45.0 \\
\hline $\mathrm{CaF}_{2}$ & 12.0 \\
\hline $\mathrm{Ca}_{3}\left(\mathrm{PO}_{4}\right)_{2}$ & 10.0 \\
\hline $\mathrm{CaCO}_{3}$ & 12.0 \\
\hline
\end{tabular}

Table 1-1. Compositions of various glass ionomers 


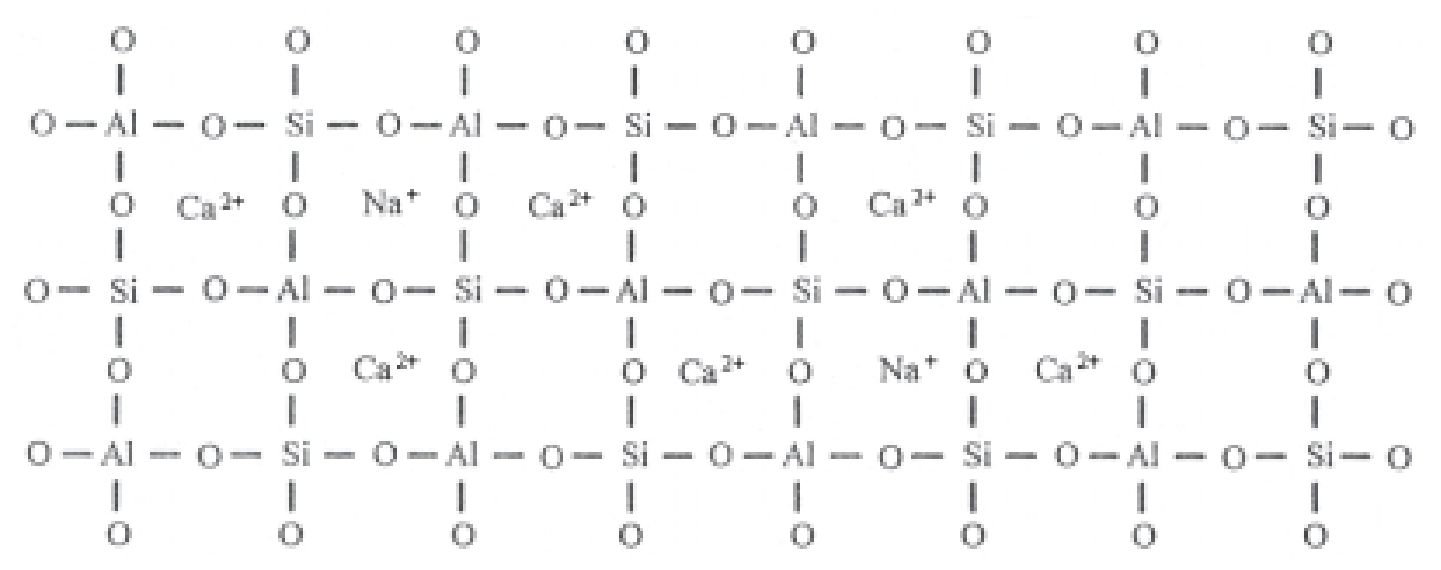

Figure 1-1. Structure of calcium aluminosilicate ${ }^{[7]}$

and maleic acid copolymers. The structures of these polymers are depicted in Figure 1-2.

Upon mixing the polyacid and glass ionomer, an acid-base reaction occurs. ${ }^{[8]}$ In the early stages of the reaction, the glass powder is decomposed by the polyacid. The polyacid contains carboxyl $(-\mathrm{COOH})$ groups which ionize to carboxylate $\left(-\mathrm{COO}^{-}\right)$ions and hydrogen $\left(\mathrm{H}^{+}\right)$ions. The schematic structure of ionization of the polyacid is shown in Figure 1-3. The glassionomer powder contains free aluminium ions which enter the silica network, replace silicon, and therefore confer a negative charge to the network, which becomes basic (in a Lewis acid/base sense). Next, metal ions $\left(\mathrm{Ca}^{2+}\right.$ and $\left.\mathrm{Al}^{3+}\right)$ are replaced by $\mathrm{H}^{+}$ions and released from the glass ionomer. Sequentially, metal ions form complex ions with six $\mathrm{H}_{2} \mathrm{O}$ molecules, i.e. $\left[\mathrm{Ca}\left(\mathrm{H}_{2} \mathrm{O}\right)_{6}\right]^{2+}$ and $\left[\mathrm{Al}\left(\mathrm{H}_{2} \mathrm{O}\right)_{6}\right]^{3+}$. ${ }^{[10]}$ Then $-\mathrm{COO}^{-}$ions react 
with these complex ions to form calcium and aluminium polysalts (see Figure 1-4). ${ }^{[8,10]}$ Silica gel is also formed by addition of $\mathrm{H}^{+}$ions and loss of $\mathrm{Al}^{3+}$ ions from the aluminosilicate (see Figure 1-5). ${ }^{[7,11]}$ Also, polymer crosslinks are formed in the case of resin modified glass-ionomer cements (see detailed discussion in Chapter 3). Subsequently, hardening and curing

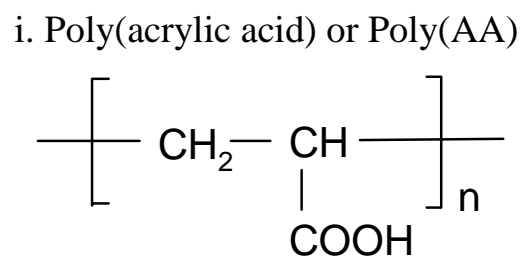

ii. Poly(acrylic acid-co-itaconic acid) or Poly(AA-co-IA)

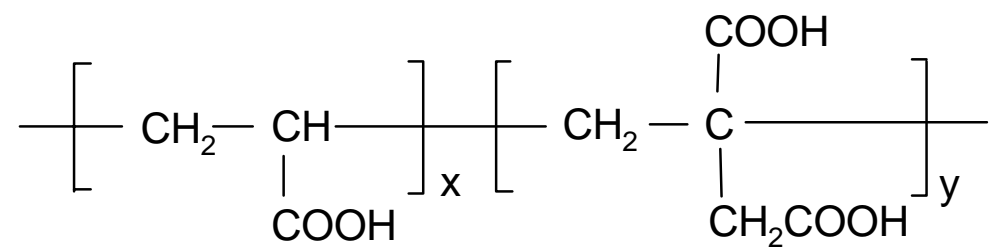

iii. Poly(acrylic acid-co-maleic acid) or Poly(AA-co-MA)

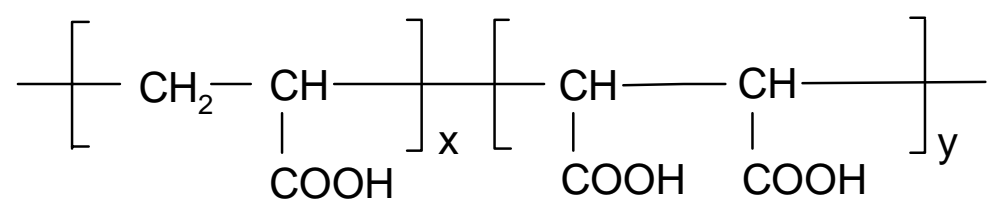

Figure 1-2. Schematic structures for polyacid homo- or copolymers

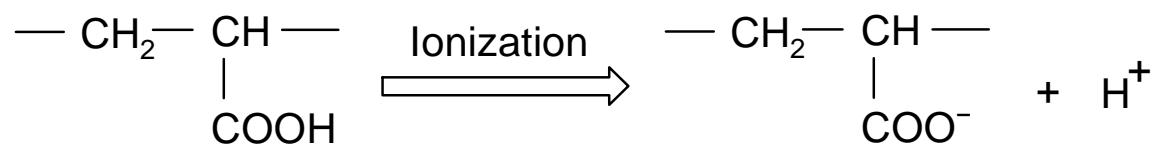

Figure 1-3. Schematic structure of ionization of polyacid 
of the cement paste occurs due to the silicate network reconstruction by elimination of the aluminum and water, ${ }^{[11]}$ along with release of fluoride ions. ${ }^{[8,12]}$ Fluoride is an essential constituent of the glass-ionomer cement because it improves the working properties of the cement paste and increases the strength of the cement. ${ }^{[8]}$ Fluoride ions are released from the glass ionomer and form metal complexes $\left(\mathrm{AlF}^{2+}\right.$ and $\left.\mathrm{CaF}^{+}\right)$which retard the binding of the metal cations to the carboxylate anions on the polyacid chain, thus delaying the formation of polysalts, and therefore prolonging the working time ${ }^{*}{ }^{[8]}$ Formation of these complexes (i.e. $\mathrm{AlF}^{2+}$ and $\mathrm{CaF}^{+}$) also

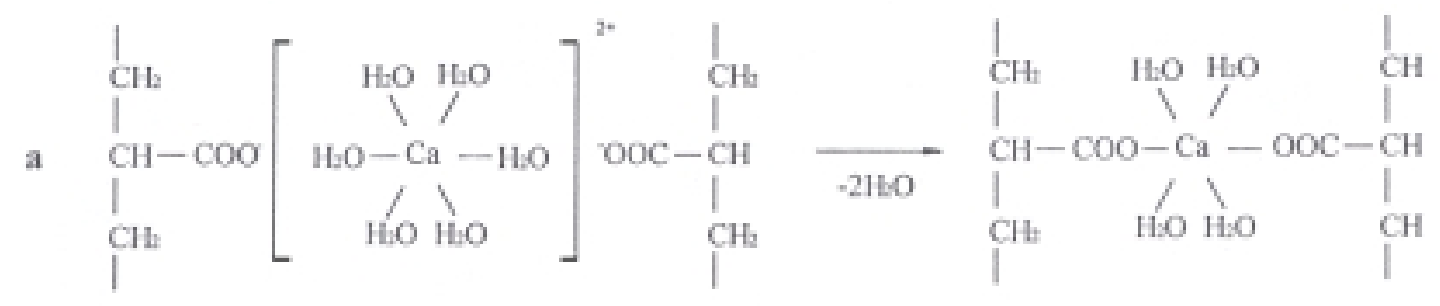

b

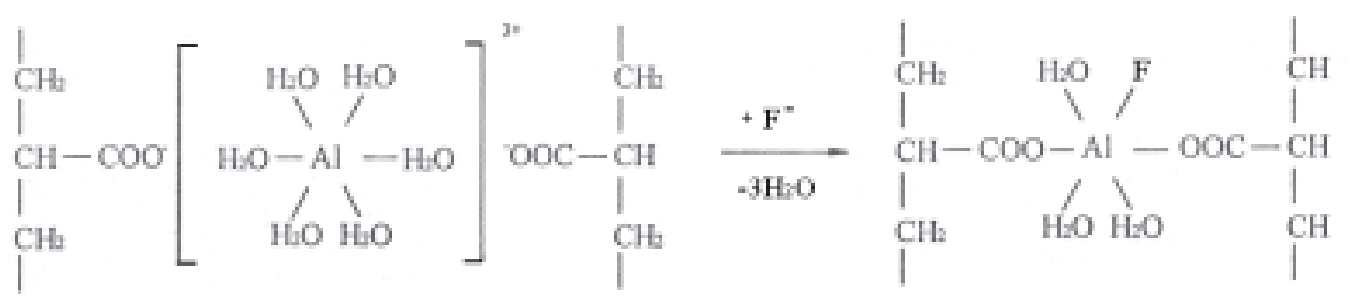

Figure 1-4. Representative reactions in the formation of metal polyacrylate salts: ${ }^{[8,10]}$

a) $-\mathrm{COO}^{-}$ions react with $\left[\mathrm{Ca}\left(\mathrm{H}_{2} \mathrm{O}\right)_{6}\right]^{2+}$ complex ions;

b) $-\mathrm{COO}^{-}$ions react with $\left[\mathrm{Al}\left(\mathrm{H}_{2} \mathrm{O}\right)_{6}\right]^{3+}$ complex ions along with $\mathrm{F}^{-}$ions.

\footnotetext{
"Working time - The time between the beginning of the setting reaction, and the time the setting reaction has proceeded to the point at which it is no longer practical to perform further physical work upon the system for its intended dental or medical purpose. ${ }^{[13]}$
} 

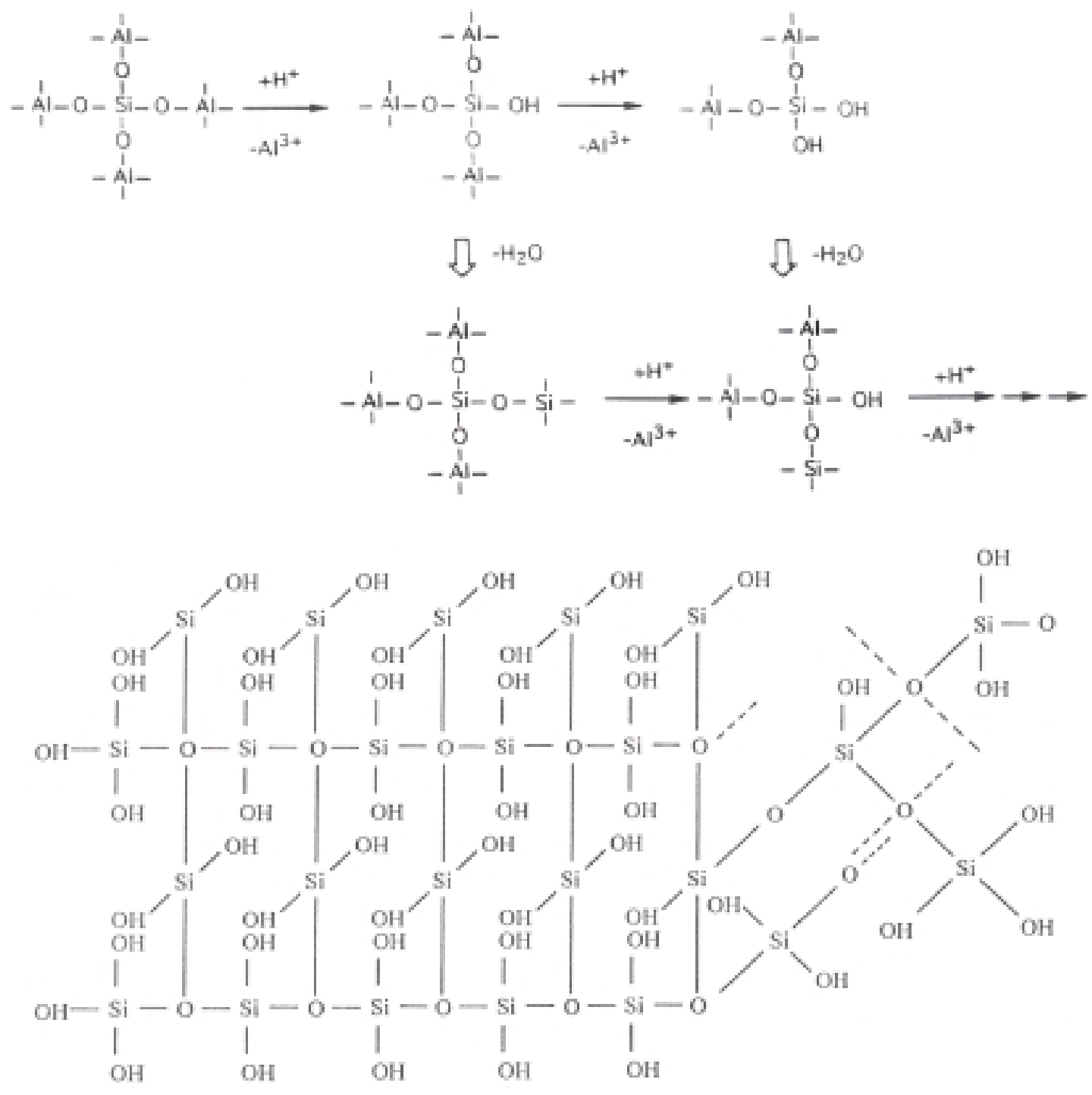

Figure 1-5. Schematic structure of formation of silica gel ${ }^{[7,11]}$

releases hydrogen ions, thus increasing the acidity of the cement paste and delaying $\mathrm{pH}$-dependent gelation, which results in longer working time. ${ }^{[8,14]}$

The overall reaction scheme of glass-ionomer cements is shown in Figure 1-6. It should be noted that not all the - $\mathrm{COOH}$ groups of the polyacid 
are converted to $-\mathrm{COO}^{-}$groups and $\mathrm{H}^{+}$ions. ${ }^{[8]}$ This is because some $-\mathrm{COOH}$ groups are sterically hindered and thus inaccessible, and also because of the hindrance of further loss of $\mathrm{H}^{+}$ions caused by the ionization process due to the increased negative charge on the polyacid chain and the electrostatic forces of repulsion due to the high concentration of $\mathrm{H}^{+}$ions in the solution. ${ }^{[15]}$

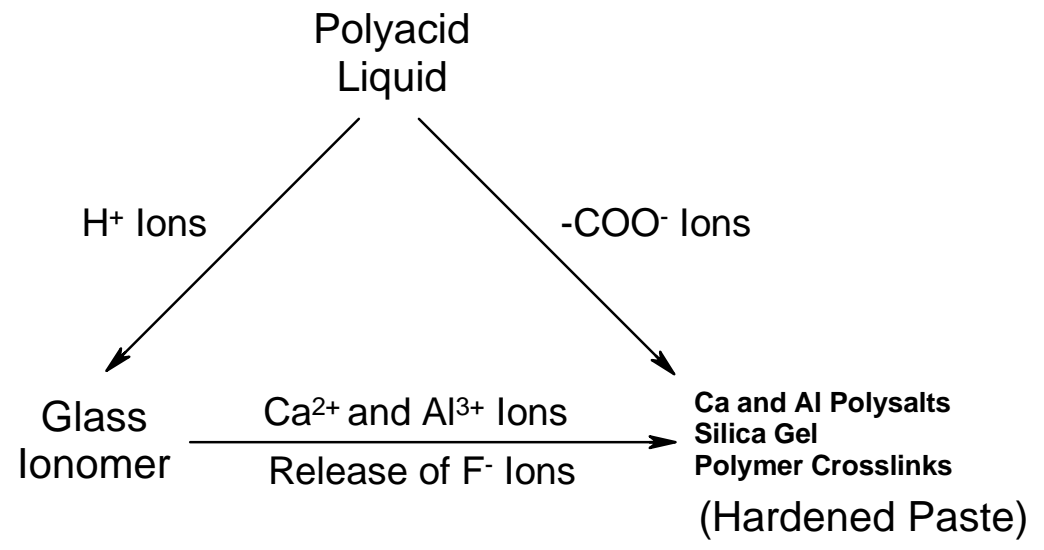

Figure 1-6. Overall reaction scheme of glass-ionomer cements

It has been concluded that the formation of metal polyacrylate salts is responsible for the early hardening of glass-ionomer cements and that the reconstruction of the silicate network contributes to the increase in strength with time during the period after the polysalt and silica gel formation. ${ }^{[11,16]}$

Based on previous studies, Wilson and McLean ${ }^{[8]}$ listed several factors affecting the rate of setting: 
1) Composition of the glass ionomer. The higher the alumina/silica ratio, the faster the set and the shorter the working time; the higher the concentration of the fluoride the longer the working time.

2) Particle size of the glass. The finer the powder the faster the set and the shorter the working time.

3) Addition of tartaric acid. The setting time ${ }^{* *}$ can be shortened without shortening the working time by addition of tartaric acid. Tartaric acid works as a chelating agent which forms an unstable cement (during the early part of the reaction) due to metal tartrate complex formation (see Figure 1-7). The role of tartaric acid is similar to that of fluoride ions. The formation of

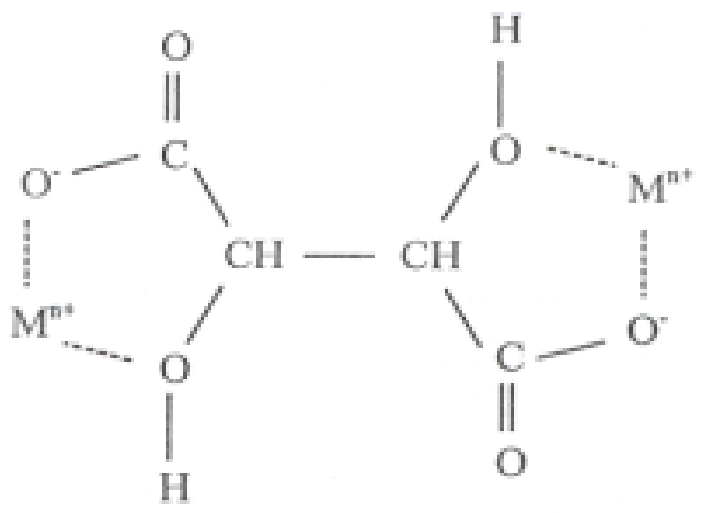

Figure 1-7. Metal tartrate complex ${ }^{[8]}$

\footnotetext{
${ }^{* *}$ Setting time - The time between the beginning of the setting reaction, and the time the sufficient hardening has occurred to allow subsequent clinical procedures to be performed on the surface of the dental cement. ${ }^{[13]}$
} 
tartrate complexes delays the onset of setting and improves the handling properties. Tartaric acid also makes the set proceed rapidly by accelerating the precipitation process. In addition, tartaric acid increases the cement strength (during the later stages of the reaction). Although the mechanism of action of tartaric acid on the cement has not been completely clarified, it is known that: a) tartaric acid can form strong complexes with aluminium, thus enhancing extraction of aluminium from the glass; b) upon mixing the cement, tartaric acid forms the first complexes with metal ions due to its higher $\mathrm{K}_{\mathrm{a}}$ values (compared to the polyacid). This suppresses the ionization of the polyacid and retards the unwinding of the polyacid chain, thus delaying gelation; c) once gelation occurs, tartaric acid accelerates hardening; d) the initial setting of the cement is controlled by tartaric acid due to the formation of calcium tartrate.

4) Relative glass/polyacid/tartaric acid/water ratios in the cement mixture. The higher the proportion of glass and the lower the proportion of water, the faster the set and the shorter the working time. When the optimum ratio is passed, there is not 
enough water for the reaction and for hydration, resulting in a weakened cement. However, too much water also leads to a weak and slow-setting cement.

5) Temperature of mixing. The higher the temperature the faster the set and the shorter the working time.

Since Wilson, et al. ${ }^{[6]}$ introduced glass-ionomer cements to the dental community in 1971, different approaches have been used to investigate such reactions to improve the working properties of the glass-ionomer dental cements (longer working time and shorter setting time are preferred). In order to obtain the optimum conditions, alumina/silica ratios and fluoride concentrations were varied. ${ }^{[8,17]}$ In order to obtain faster setting without shortening the working time, tartaric acid was added to the polyacid. ${ }^{[8,17]}$ Previously, Kao, et al. ${ }^{[18]}$ studied the effects of adding side chains of different lengths and compositions to the backbone of the polyacid to increase the irregularity of the polyacid structure and hence the accessibility of the carboxyl groups.

In our current study, we used emission spectroscopic techniques to monitor the setting reactions of different types of new modified polyacids with Fuji II glass-ionomer powder. This was accomplished by determining 
the integrated peak intensities of emission signals arising from chromium $\left(\mathrm{Cr}^{3+}\right)$ ions in the aluminium oxide $\left(\mathrm{Al}_{2} \mathrm{O}_{3}\right)$ matrix ${ }^{[19]}$ as a function of reaction time. We monitored the setting reactions in order to elucidate the effects of the concentrations of $\mathrm{H}^{+}$ions in the modified polyacids due to the different structures.

In this study, emission spectroscopy was also used to monitor resin modified glass-ionomer dental cements. The setting reaction and the formation of polysalts were compared with and without irradiation. We have been able to illustrate the effects of the light-induced polymerization on polysalt formation and the times of completion of the setting reaction.

\subsection{EMISSION SPECTROSCOPY}

The general mechanism of electronic processes is described as follows: a molecule absorbs a photon and is excited from a ground electronic state (often a singlet state, $S_{0}$ ) to an excited electronic state (often $S_{1}$ ). The molecule can drop to the lowest vibrational level of the excited electronic state by non-radiative processes, e.g. vibrational relaxation $\left(\mathrm{R}_{1}\right)$, and then return to the ground electronic state by a radiative process (emission of light), that is, fluorescence in the case of a singlet-singlet transition (F). The 
process diagram is shown in Figure 1-8.

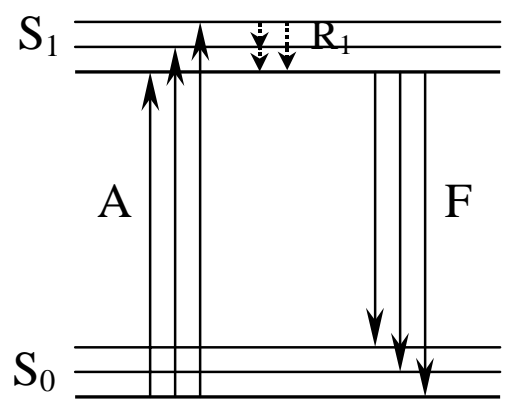

Figure 1-8. Diagram of electronic processes

We have used emission spectroscopy in our study of dental cements. Our method using emission spectroscopy has many advantages:

1) The glass-ionomer cements are water-based materials and water plays an important role in the setting and structure. ${ }^{[8]}$ In many spectroscopic techniques, water can cause interference. But water is a very good solvent for our emission spectroscopic method and provides no interference.

2) Emission spectroscopy works particularly well with polymers. It can be used to quantitatively analyze polymers. ${ }^{[20]}$

3) Our spectroscopic technique is much easier than previously reported methods using atomic absorption spectrometry, ${ }^{[14]}$ since we do not need to quench the reaction, but can 
periodically collect spectra during the course of the reaction.

4) Extraneous fluorescence interference is minimized while the emission spectrum of the cement can be collected. The excitation frequency used in our experiments is lower in energy than required for fluorescent excitation of most molecular systems. Therefore strong fluorescent interference is usually not a significant problem.

One difficulty in our emission-based process is that fluorescence can still occur due to small amounts of fluorescent impurities or inherent fluorescence of the polymer itself. Even in nominally non-fluorescent materials, this can be very strong and completely mask the very weak emission signals from the polymer. Some polymers, e.g. polyamides, polyesters, polyvinyl fluoride, and polyacrylonitrile, suffer from this problem even when great care is taken in the preparation of the sample. ${ }^{[20]}$ Due to this difficulty we investigated the fluorescence spectra of six conventionally cured and two resin modified polyacids to explain how fluorescence affects the emission signals. 


\section{REFERENCES}

1. G. J. Christensen, JADA, 125, 1257-8, 1994

2. A. D. Wilson, Int. J. Prosthodont., 2, 438-446, 1989

3. S. K. Sidhu, and T. F. Watson, Am. J. Dent., 8(1), 59-67, 1995

4. A. D. Wilson, Int. J. Prosthodont., 3, 425-429, 1990

5. J. W. McLean, Dent. Clin. North. Am., 36(3), 693-711, 1992

6. A. D. Wilson and B. E. Kent, J. Appl. Chem. Biotechnol., 21, 313, 1971

7. S. Katsuyama, T. Ishikawa, and B. Fujii, Glass Ionomer Dental Cement, Ishiyaku EuroAmerica, Inc. Publishers, St. Louis, MO, 1993

8. A. D. Wilson and J. W. McLean, Glass-Ionomer Cement, Quintessence Publishing Co., Inc., Chicago, IL, 1988

9. S. Akahane, et al., Dental Glass Ionomer Cement Compositions, U.S. patent: 5,063,257, Nov.5, 1991

10. S. Crisp, J. Dent. Res., 55, 299-308, 1976

11. S. Matsuya, T. Maeda, and M. Ohta, J. Dent. Res., 75(12), 1920-1927, 1996

12. A. Tiba, B. M. Culbertson, and L. J. Berliner, J.M.S.-Pure App. Chem., A35(9), 1445-1457, 1998 
13. S. B. Mitra, Photocurable Ionomer Cement Systems, U.S. patent: 5,130,347, Jul.14, 1992

14. S. Crisp and A. D. Wilson, J. Dent. Res., 53, 1408-1413, 1974

15. D. Xie, B. M. Culbertson, and W. M. Johnston, J.M.S.-Pure Appl. Chem., A35(10), 1615-1629, 1998

16. E. A. Wasson and J. W. Nicholson, J. Dent. Res., 72(2), 481-483, 1993

17. Z. Ouyang, Glass Ionomer Cements: Understanding the Effects of Polyacid Substitution and Light Induced Polymerization, M.S. Thesis, West Virginia University, 1997

18. E. C. Kao, B. M. Culbertson, and D. Xie, Dent. Mater., 12, 44-51, 1996

19. M. D. Lumb, Luminescence Spectroscopy, Academic Press, London, 9-13, 1978

20. D. O. Hummel, Polymer Spectroscopy, Verlag Chemie GmbH, Weinheim/Bergstv, Germany, 1974 


\section{CHAPTER 2}

\section{SPECTROSCOPIC INVESTIGATIONS OF MODIFIED CONVENTIONALLY CURED GLASS-IONOMER DENTAL CEMENTS}

\subsection{INTRODUCTION}

As previously mentioned, not all the $-\mathrm{COOH}$ groups are involved in the formation of polysalts and polymer crosslinks because of the sterically restricted access to metal ions caused by the network and the locally increased negative charge on the polyacid chain. Several methods have been used to study how to involve more $-\mathrm{COOH}$ groups in the reaction. One of the methods is to add side chains of different lengths and compositions to the backbone of the polyacid in order to increase the irregularity of the polyacid structure. $^{[1]}$

In our study, Fuji II conventional glass ionomer was mixed with various modified polyacids. We monitored the setting reactions based on the integrated peak intensities of emission signals due to $\mathrm{Cr}^{3+}$ ions in the $\mathrm{Al}_{2} \mathrm{O}_{3}$ matrix ${ }^{[2]}$ and compared the different setting times due to the different 
concentrations of $\mathrm{H}^{+}$ions available in the modified polyacids with the different polyacid structures.

\subsection{EXPERIMENTAL}

\section{Materials}

Commercially available conventional glass-ionomer dental cement Fuji II (GC Corporation, Tokyo, Japan) (F2 C) was used as the control in this study.

$\mathrm{N}$-Vinylpyrrolidone (NVP) and N-methacrolylglutamic acid (MGA) were used to modify polyacids. The structures of three representative polyacids are shown in Figure 2-1. Component ratios and abbreviation codes for the different polyacids used in this study are listed in Table 2-1. All solid modified polyacids were supplied by Prof. Elizabeth C. Kao in the School of Dentistry at West Virginia University and Prof. Bill M. Culbertson in the School of Dentistry at Ohio State University.

Aluminium oxide $\left(\mathrm{Al}_{2} \mathrm{O}_{3}\right)$ used as a reference in this study was $\alpha-\mathrm{Al}_{2} \mathrm{O}_{3}$ obtained from the Johnson Matthey Company, Ward Hill, MA. The purity of the $\alpha-\mathrm{Al}_{2} \mathrm{O}_{3}$ is $99.99 \%$. Water used in the study was nanopure water which was prepared in Department of Chemistry at West Virginia 
University. Activated carbon, methanol and ether (used as received from Fisher Scientific, Pittsburgh, PA) were used to purify several polyacids.

i. Poly(acrylic acid-co-itaconic acid-co-N-vinylpyrrolidone) or Poly(AA-co-IA-co-NVP)

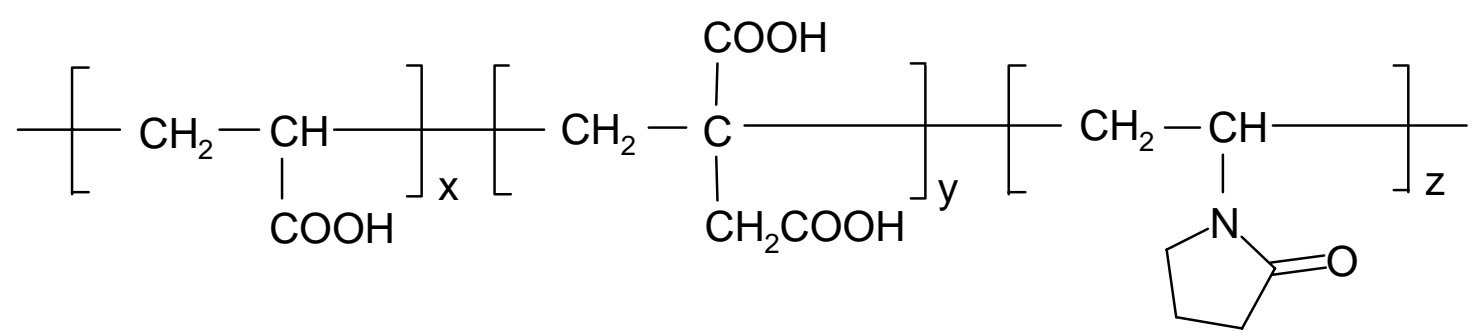

ii. Poly(acrylic acid-co-maleic acid-co-N-vinylpyrrolidone) or Poly(AA-co-MA-co-NVP)

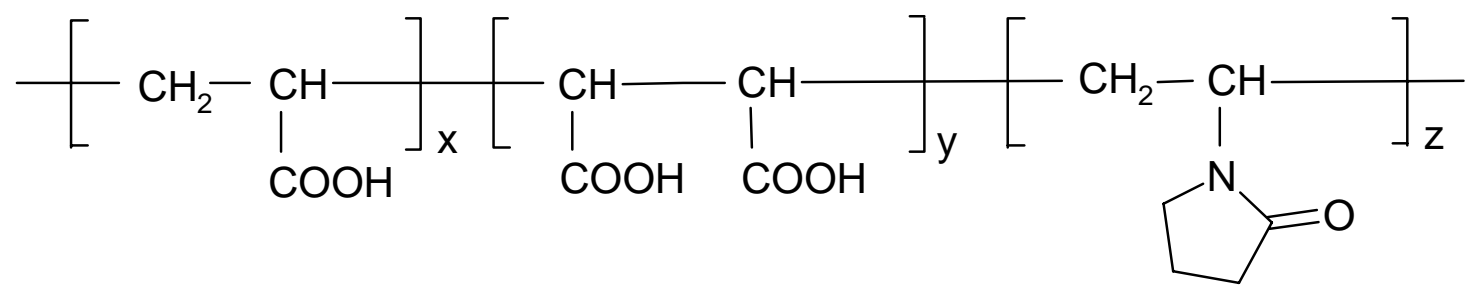

iii. Poly(acrylic acid-co-itaconic acid-co-N-methacrolylglutamic acid) or Poly(AA-co-IA-co-MGA)

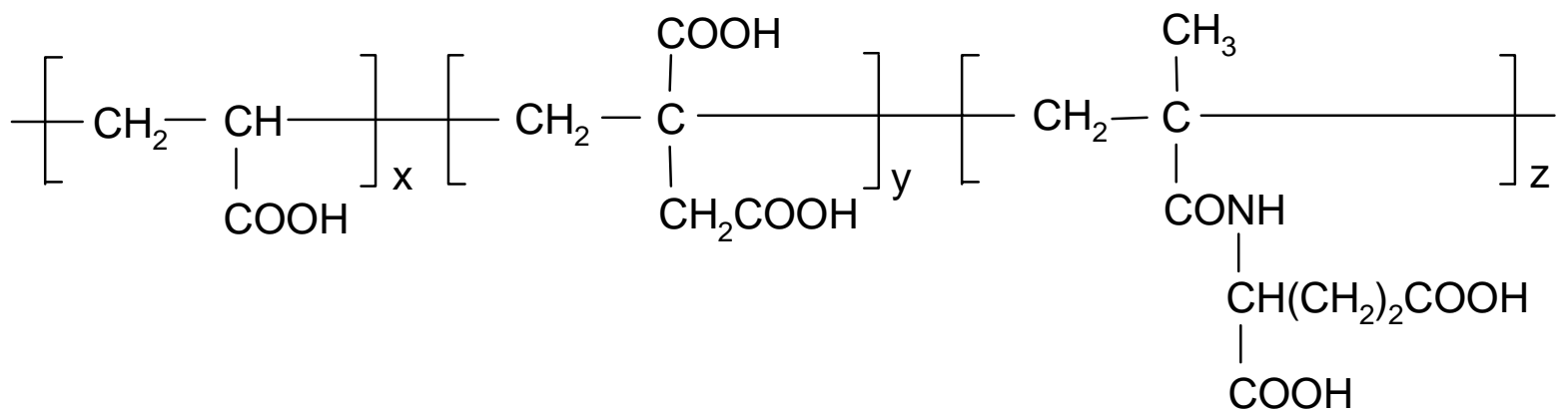

Figure 2-1. Schematic structures for copolymers used in this study. 


\begin{tabular}{|c|c|c|}
\hline Components & Ratio & Code \\
\hline AA $:$ IA & $2: 1$ & F2 C \\
\hline AA $:$ MA $:$ NVP & $7: 3: 1$ & AMN731 \\
\hline AA $:$ MA $:$ NVP & $7: 1: 3$ & AMN713 \\
\hline AA $:$ IA $:$ MGA & $8: 1: 1$ & AIM811 \\
\hline AA $:$ IA $:$ NVP & $7: 1: 3$ & AIN713 \\
\hline AA : IA : NVP & $8: 2: 1$ & AIN821 \\
\hline
\end{tabular}

Table 2-1. Polyacids used in the study

\section{Sample Purification}

Two methods were used to purify several polyacids. One method was to add activated carbon to polyacid solutions and let them sit for 2 hours, and then remove the charcoal. The second method was to completely dissolve solid polyacid in methanol, let it stay for 1 hour, then precipitate it by ether, and finally dry the polyacid under vacuum for two days.

\section{Sample Preparation}

Water in the F2 C liquid polyacid was extracted under vacuum for three days. Dried solid F2 C polyacid or any other solid modified polyacid was dissolved in water with a weight ratio of polyacid : water of $1: 5.5$ 
using an ultrasonic cleaner (E/MC; Model 250; USA) for agitation to promote dissolution. The concentrations of the polyacid solutions used were lower than those of liquid polyacids in the commercial systems, but higher than those of polyacid solutions previously reported. ${ }^{[3,4]}$ This is because diluted solutions will slow the reaction, thus it can be more easily monitored. Also, the glass ionomers can be easily mixed with more dilute polyacid solutions thus improving the reproducibility of the results. However, solutions at very low polyacid concentrations lead to lower intensity spectra and thus to decreased signal-to-noise ratios. Furthermore, the setting reaction will go further toward completion at a higher concentration of polyacids, i.e. forcing the glass ionomer to react completely. The glass-ionomer powders were rapidly mixed with the polyacid solutions in a glass powder : polyacid : water weight ratio of $2.7: 1: 5.5$ and loaded into a standard capillary tube within one minute.

\section{Spectroscopy and Data Processing}

The capillary tube loaded with the sample was placed in the spectrometer. Spectra were collected within the first minute and then every 5 minutes for 2 hours with each scan lasting 6 seconds (shorter scan times resulted in a weaker signal, while longer scan times did not provide 
significantly stronger signals). The laser beam was blocked between the scans to avoid any photodecomposition of the cement. The spectrum of each sample type was collected 12-14 times with new preparations on separate days and the reproducibility for each data processing shown was consistent (see Appendices for standard errors).

We know that in the glass ionomer, $\mathrm{Cr}^{3+}$ in the $\mathrm{Al}_{2} \mathrm{O}_{3}$ matrix leads to a strong emission signal, so an emission spectrum of solid $\mathrm{Al}_{2} \mathrm{O}_{3}$ was collected for reference. ${ }^{[2]}$ Solid $\mathrm{Al}_{2} \mathrm{O}_{3}$ was loaded into a standard capillary tube and placed in the spectrometer. The spectrum was collected with a 6-second scan.

During all the experiments we used a laser spectrometer consisting of a Lexel RamanIon krypton-ion laser (Fremont, CA) with 0.4 W (low power is preferred to avoid photodecomposition) of optical power (at the laser) with laser excitation at $647.1 \mathrm{~nm}$ [it has been suggested that this red wavelength (i.e. $\mathrm{Kr}^{+}, 647.1 \mathrm{~nm}$ ) is the most universally applicable for polymers $\left.{ }^{[5]}\right]$. A $90^{\circ}$ geometry was used for collection of scattered radiation. The spectrometer was calibrated with indene (the spectrum of indene is shown in Figure 2-2), so all wavenumbers are accurate to $\pm 2 \mathrm{~cm}^{-1} .{ }^{[6]} \mathrm{We}$ used a Spex Industries DM3000 Ramalog/Triplemate System (Edison, NJ), which is equipped with 600 grooves/nm gratings and a CCD detector 
operating at about $137 \mathrm{~K}$ to analyze the signals. Integrated peak areas of the spectral bands were calculated in order to compare peak intensities as a function of time.

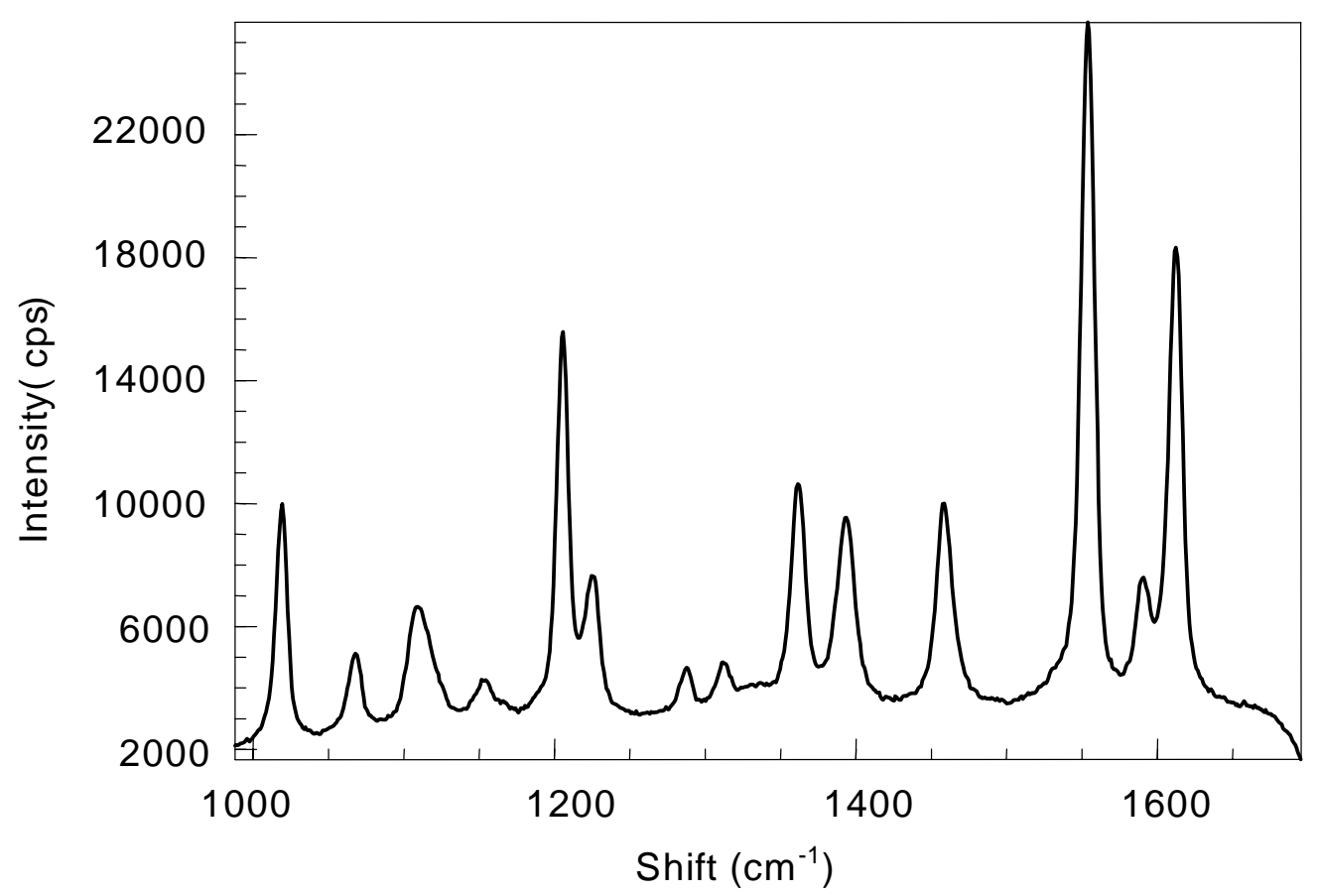

Figure 2-2. Emission spectrum of indene

\section{Statistical Analysis}

For the samples in each group, all experiments were repeated 12-14 times. Statistical tests ( $\mathrm{Q}$ test and $\mathrm{T}_{\mathrm{n}}$ test) were used to provide criteria for rejection or retention of outlying data and to determine the significant differences among the samples tested in each group. If the experimental Q or $T_{n}$ value was greater than the critical value, the questionable result was rejected based on the null hypothesis; otherwise, the result was retained. ${ }^{[7]}$ 


\section{Characterization of Polyacids}

A Fisher Scientific Accumet pH Meter (Denver Instrument Co., USA) was used to characterize the modified polyacids. $\mathrm{pH}$ values of the four modified polyacid solutions for which emission spectra were analyzed were collected 3 times with three separate preparations of polyacid solutions (the concentrations of the polyacid solutions are the same as those used in the setting reactions, i.e. polyacid $:$ water $=1: 5.5$ by weight). The different $\mathrm{pH}$ values of the modified polyacids were used to understand the setting reaction completion times due to the different concentrations of $\mathrm{H}^{+}$ions available from the polyacids.

\section{Fluorescence Spectroscopy}

The fluorescence of modified polyacids was investigated using a Fluorolog-3 spectrofluorometer (Model FL3-11; Instruments S.A., Inc., USA) with a $450 \mathrm{~W}$ xenon source, a PMT detector, and DataMax for Windows $^{\mathrm{TM}}$ software. The excitation wavelength was $350 \mathrm{~nm}$, the integration time was $1 \mathrm{~s}$, and the scan range was $360 \mathrm{~nm}-680 \mathrm{~nm}$. The cell we used was a quartz cell (Type: $3 / \mathrm{Q} / 10$ ) and its pathlength was $10 \mathrm{~mm}$.

We compared the fluorescence signals of the six modified polyacids of different properties used in this study. For consistency, the concentrations 
of modified polyacids used were the same as those of the polyacids used in spectroscopic method (i.e. polyacid : water $=1: 5.5$ by weight).

\subsection{RESULTS AND DISCUSSION}

\section{Spectroscopic Investigations of Different Dental Cements}

Typical emission spectra of the setting reaction of $\mathrm{F} 2 \mathrm{C}$ glass-ionomer powder and the polyacid of AMN731 are shown in Figure 2-3. For comparison, the spectrum of pure $\mathrm{Al}_{2} \mathrm{O}_{3}$ is presented in Figure 2-4. In both the cement and pure $\mathrm{Al}_{2} \mathrm{O}_{3}$, two strong bands at $1030 \mathrm{~cm}^{-1}$ and $1058 \mathrm{~cm}^{-1}$ were found to the red side of the incident laser wavenumbers $\left(14,423 \mathrm{~cm}^{-1}\right.$ and $14,395 \mathrm{~cm}^{-1}$ ). The intensities of the spectral peaks (due to the emission of $\mathrm{Cr}^{3+}$ ions in the $\mathrm{Al}_{2} \mathrm{O}_{3}$ matrix within the cement mixture) decrease quickly as a function of the reaction time. The decrease of the peak intensities illustrates that the glass ionomer (specifically the $\mathrm{Al}_{2} \mathrm{O}_{3}$ matrix) is decomposing and the metal ions are being released. The initial hardening time of the paste is determined by the completion time of polysalt formation with fast polysalt formation leading to rapid setting. The higher the concentration of metal ions released from the glass ionomer, the higher the concentration of polysalts that are formed. Higher concentrations result in a 


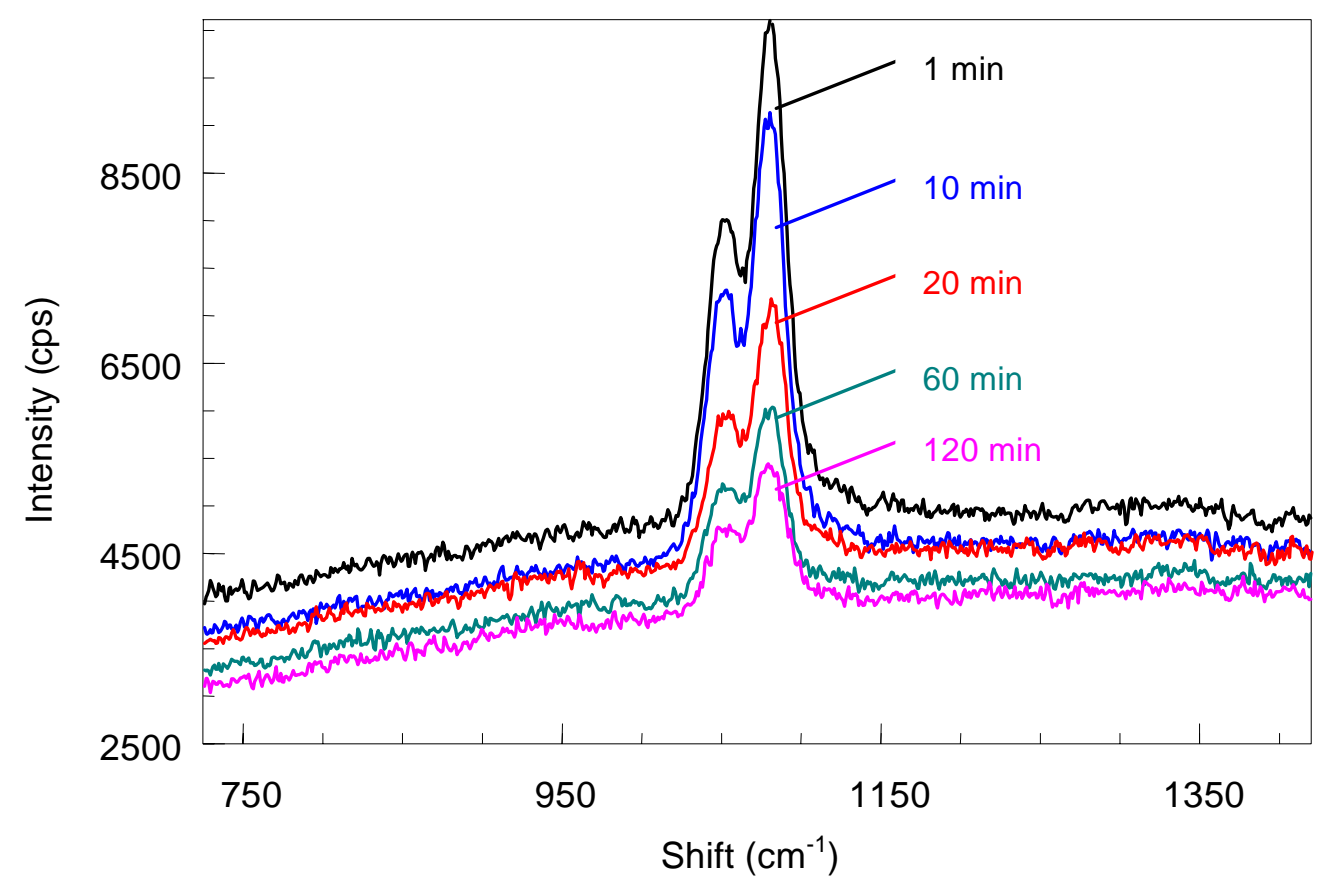

Figure 2-3. Emission spectra of F2 C glass ionomer and AMN731 polyacid dental cement as a function of reaction time. Reference is to the excitation frequency $\left(15,453.56 \mathrm{~cm}^{-1}\right)$ at $0.0 \mathrm{~cm}^{-1}$.

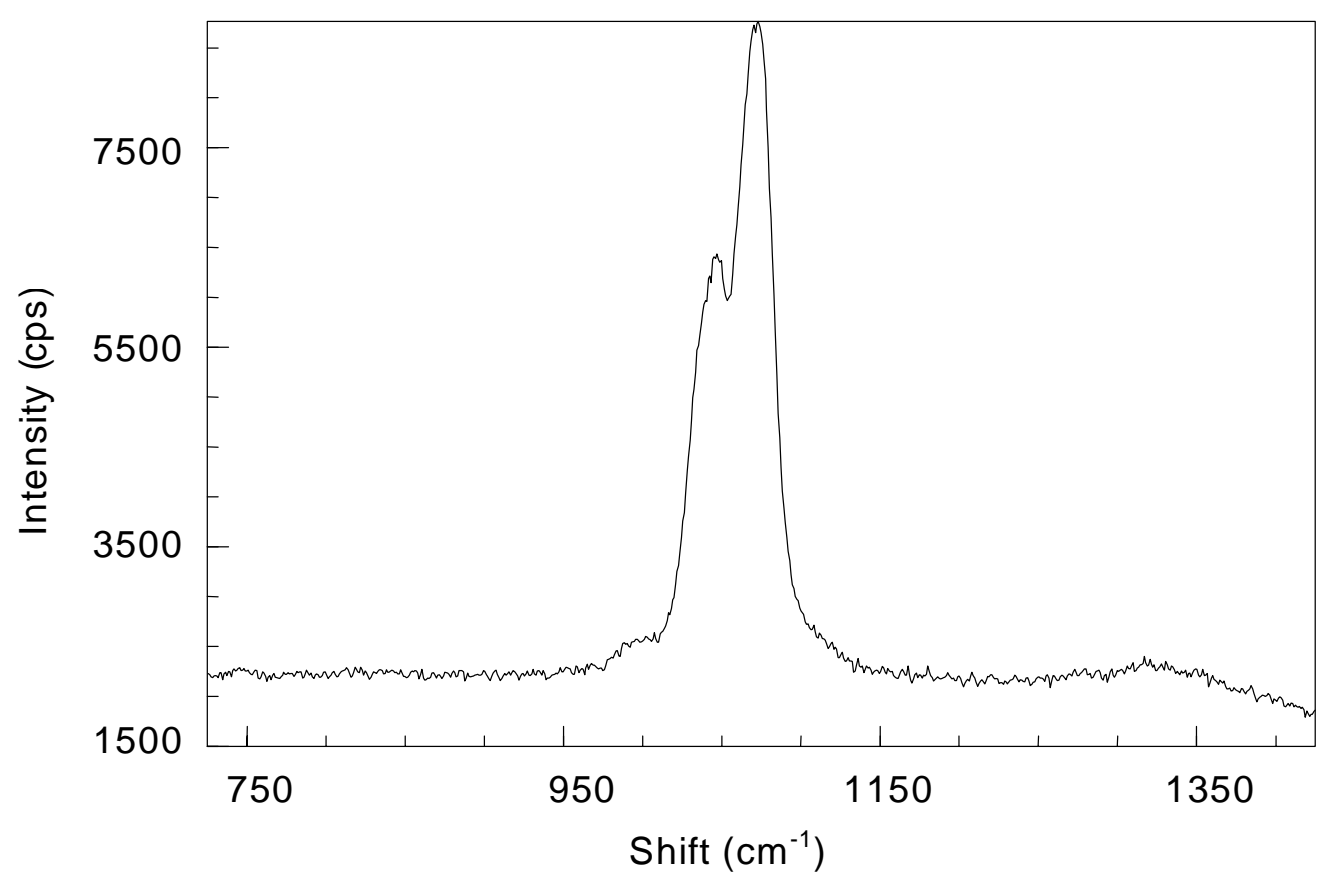

Figure 2-4. Emission spectrum of pure $\mathrm{Al}_{2} \mathrm{O}_{3}$. Reference is to the excitation frequency $\left(15,453.56 \mathrm{~cm}^{-1}\right)$ at $0.0 \mathrm{~cm}^{-1}$. 
short hardening time. The ionization of the $-\mathrm{COOH}$ groups and the concentration of $\mathrm{H}^{+}$ions that are released from the polyacid significantly affect the decomposition of the glass ionomer and the release of the metal ions (see Figure 1-6).

In our study, in order to track the concentration of $\mathrm{Al}_{2} \mathrm{O}_{3}$ due to the release of metal ions, we monitored and analyzed the normalized integrated areas of the spectral bands. The percentage of $\mathrm{Al}_{2} \mathrm{O}_{3}$ remaining in the glassionomer cement was calculated as follows: ${ }^{[3]}$

$$
\%\left(\mathrm{Al}_{2} \mathrm{O}_{3}\right)_{n}=\frac{\mathrm{I}_{n}}{\mathrm{I}_{1}} \times 100 \%
$$

Where $\%\left(\mathrm{Al}_{2} \mathrm{O}_{3}\right)_{n}$ is the percentage of $\mathrm{Al}_{2} \mathrm{O}_{3}$ left in the cement at the $n^{\text {th }}$ minute, $\mathrm{I}_{n}$ is the spectral intensity of the signal due to $\mathrm{Cr}^{3+}$ ions in the $\mathrm{Al}_{2} \mathrm{O}_{3}$ matrix at the $n^{\text {th }}$ minute, and $\mathrm{I}_{l}$ is the spectral intensity of the signal due to $\mathrm{Cr}^{3+}$ ions in the $\mathrm{Al}_{2} \mathrm{O}_{3}$ matrix at the $1^{\text {st }}$ minute. We assume that there is no release of metal ions (i.e. the reaction has not started) before the first spectrum is collected. In other words, the first minute is the practical working time and the setting time begins after the first minute. We analyzed all data based on this equation and plotted the percentage of $\mathrm{Al}_{2} \mathrm{O}_{3}$ vs. the reaction time. The results for several modified polyacids and F2 C polyacid are presented in Figure 2-5 (see Appendix A for standard errors). 


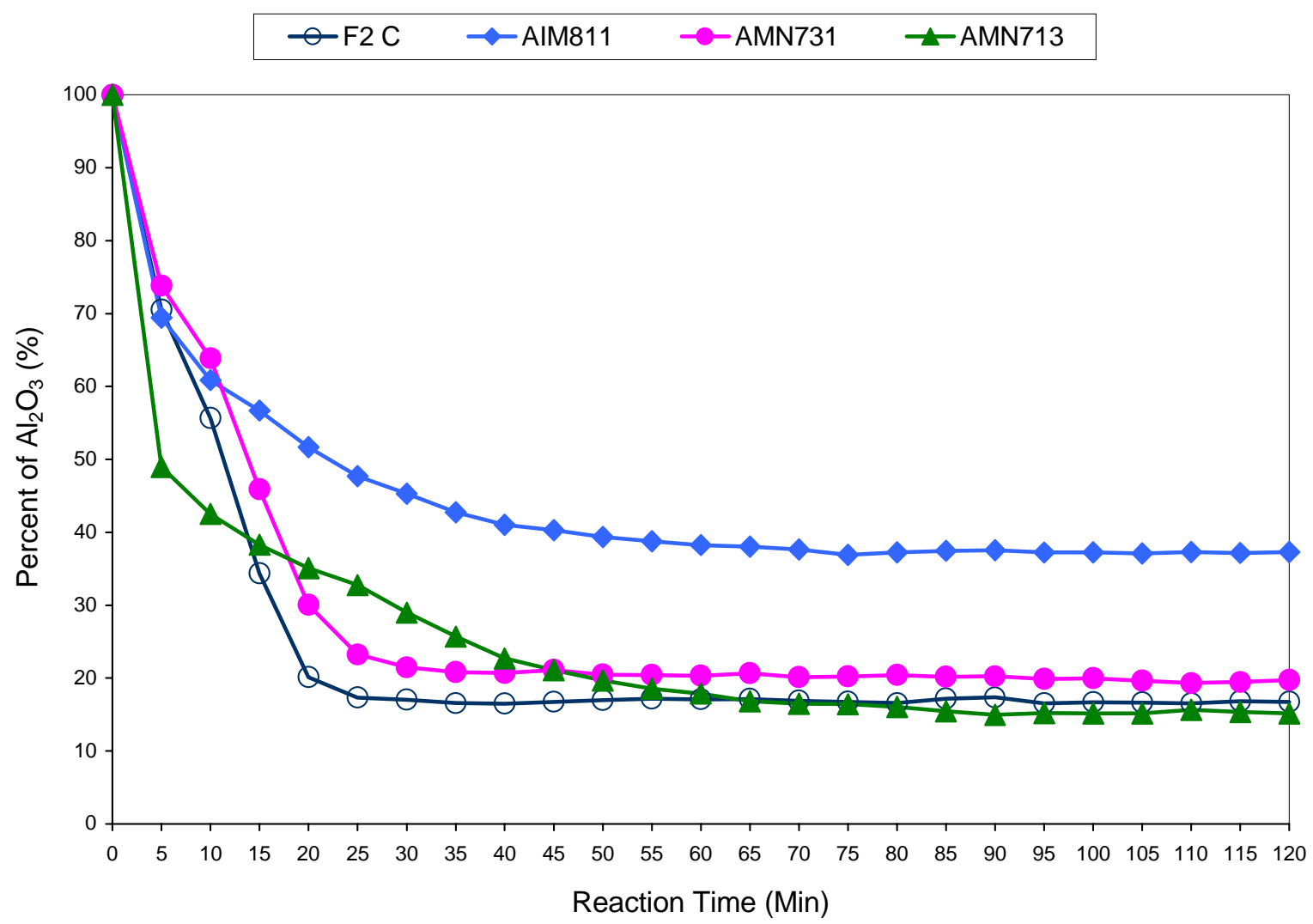

Figure 2-5. Time dependence of $\mathrm{Al}_{2} \mathrm{O}_{3}$ percent in $\mathrm{F} 2 \mathrm{C}$ glass ionomer when reacted with various polyacids shown in legend.

We found that when F2 C glass powder reacted with the different polyacids, the setting reaction was completed most quickly for $\mathrm{F} 2 \mathrm{C}$ glass powder with F2 C polyacid, which needed about 20 minutes; but relatively slowly for F2 C glass powder with AMN713 polyacid, which needed about one hour. The amount of $\mathrm{Al}_{2} \mathrm{O}_{3}$ remaining was approximately $17 \%$ (the estimated average percent of points on the flat line) for F2 C polyacid (i.e. the concentration of polysalts is high). Our finding of $17 \% \mathrm{Al}_{2} \mathrm{O}_{3}$ remaining 
was much lower than the findings of about $40 \%$ (estimated) in the previous studies. ${ }^{[3,4]}$ This is because we used a much higher concentration of polyacid which acts as an excess reagent. The amount of $\mathrm{Al}_{2} \mathrm{O}_{3}$ remaining was approximately $37 \%$ for AIM811 polyacid. The different times and $\mathrm{Al}_{2} \mathrm{O}_{3}$ percents at the completion of setting reactions are shown in Table 2-2. This reflects the fact that different polyacids have different abilities to extract $\mathrm{Al}^{3+}$ ions from the glass ionomer. This is due to the different concentrations of $\mathrm{H}^{+}$ions available from the polyacids, which are due to the different degrees of ionization of the $-\mathrm{COOH}$ groups with different polyacid structures.

The $\mathrm{pH}$ values collected for four modified polyacids (with no other components present) are listed in Table 2-2 (see Appendix C for confidence intervals). As shown in the table, $\mathrm{F} 2 \mathrm{C}$ has the lowest $\mathrm{pH}$ value (i.e. the highest concentration of $\mathrm{H}^{+}$ions) and is therefore expected to be the best of the four polyacids in extracting $\mathrm{Al}^{3+}$ ions which was verified experimentally. In previous studies, Kao, et al. ${ }^{[1]}$ and Ouyang ${ }^{[3,4]}$ demonstrated that more irregularity in the polyacid structures leads to more effective extraction of $\mathrm{Al}^{3+}$ ions. AIM has more irregular and longer side chains than AMN. Potential accessibility of $-\mathrm{COOH}$ groups and dissociation of $\mathrm{H}^{+}$ions means that AIM could have a faster setting reaction than AMN. 
Based on Figure 2-5 and Table 2-2, we see that AMN713 has the highest $\mathrm{pH}$ value, which means the worst ability to initially extract $\mathrm{Al}^{3+}$ ions. However, its ability to extract $\mathrm{Al}^{3+}$ ions by the end of the setting reaction is competitive with F2 C. The completion of the setting reaction is, however, very long (about one hour) compared to $\mathrm{F} 2 \mathrm{C}$. Although $\mathrm{H}^{+}$ions in the neat polyacid are not as available in the AMN713 as F2 C, the amide bonds on pyrrolidone rings in NVP modified polyacids are known to be very good water sorption centers ${ }^{[8,9]}$ which allow continuous dissociation of polyacids and hence metal ions are extracted for a longer period of time. Therefore NVP modified glass ionomers eventually form approximately the same amount of polysalts as $\mathrm{F} 2 \mathrm{C}$. We conclude that the $\mathrm{pH}$ of the pure polyacid solution does not provide an understanding of the availability of $\mathrm{H}^{+}$ions to the reaction components in the complex reaction mixture throughout the

\begin{tabular}{|c|c|c|c|c|c|}
\hline Components & Ratio & Code & $\begin{array}{c}p H \text { of } \\
\text { polyacid }\end{array}$ & $\begin{array}{c}\text { Time of } \\
\text { completion of } \\
\text { setting reaction }\end{array}$ & $\begin{array}{c}\mathrm{Al}_{2} \mathrm{O}_{3} \text { percent at } \\
\text { completion of } \\
\text { setting reaction }\end{array}$ \\
\hline AA : IA & $2: 1$ & F2 C & $1.73 \pm 0.02$ & $20 \mathrm{~min}$ & $17 \%$ \\
\hline AA : MA : NVP & $7: 3: 1$ & AMN731 & $1.88 \pm 0.02$ & $25 \mathrm{~min}$ & $20 \%$ \\
\hline AA : IA : MGA & $8: 1: 1$ & AIM811 & $2.01 \pm 0.02$ & $45 \mathrm{~min}$ & $37 \%$ \\
\hline AA : MA : NVP & $7: 1: 3$ & AMN713 & $2.98 \pm 0.02$ & $60 \mathrm{~min}$ & $16 \%$ \\
\hline
\end{tabular}

Table 2-2. $\mathrm{pH}$ values, time of completion of setting reaction, and $\mathrm{Al}_{2} \mathrm{O}_{3}$ percent at completion of setting reaction of various polyacids 
course of the reaction. However, it may provide some insight into the initial reactions. It can be seen in Table 2-2 that the time of completion of the setting reaction does increase with increasing $\mathrm{pH}$ of the neat polyacid.

\section{Fluorescence Spectra of Various Modified Polyacids}

The fluorescence spectra of six different modified polyacids were collected and are presented in Figure 2-6. A strong band at about $420 \mathrm{~nm}$ was found for all polyacids. The intensities of the spectra decrease in order of AIN713, AMN713, AMN731, AIM811, F2 C, and AIN821. The concentrations of all six modified polyacids were the same during the data collection (i.e. a polyacid : water weight ratio of $1: 5.5$ ) for consistency.

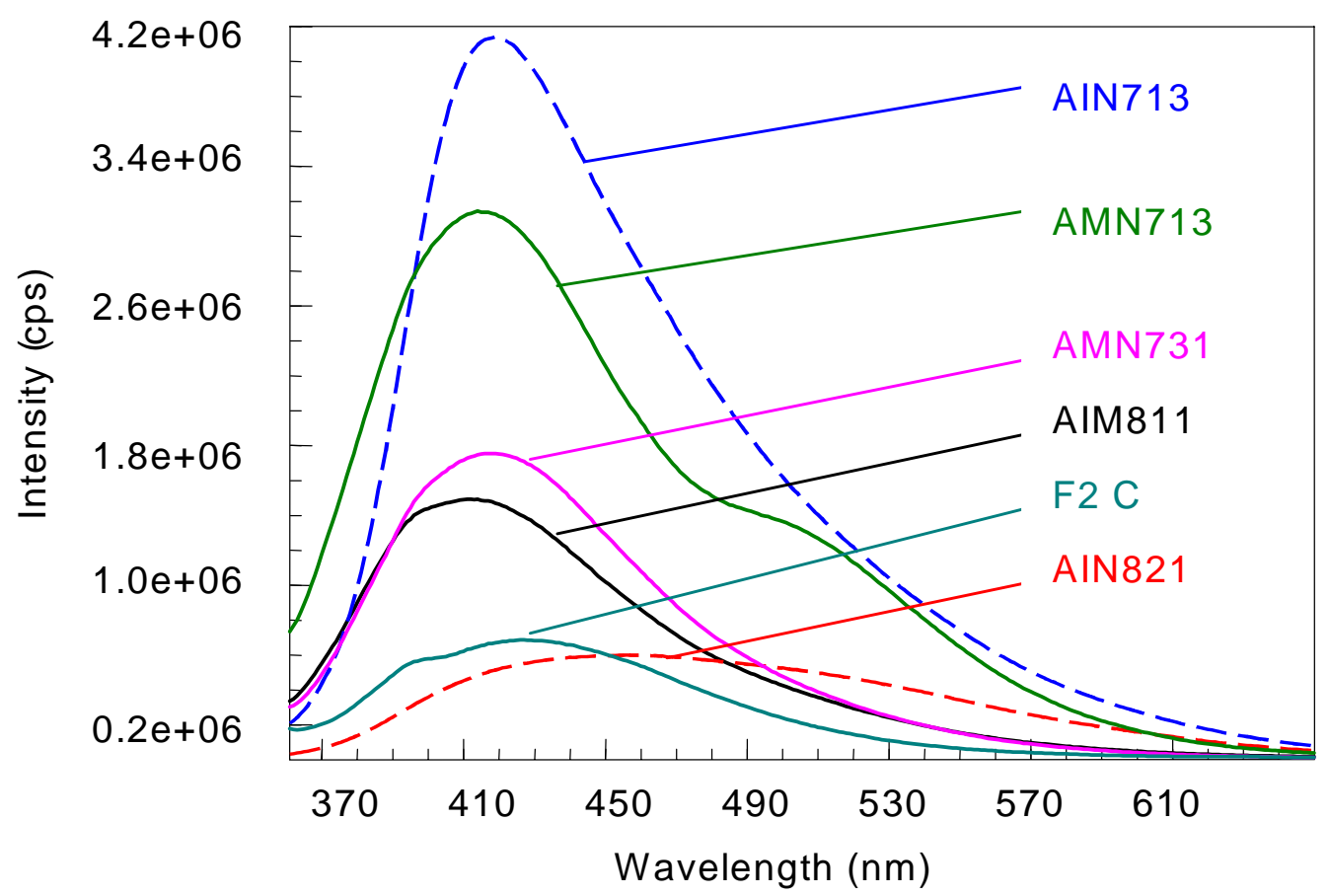

Figure 2-6. Fluorescence spectra of various polyacids 
AIN713 has very strong fluorescence, as shown in Figure 2-6. Due to this strong interference, we were not able to observe emission signals from the $\mathrm{Cr}^{3+}$ in the $\mathrm{Al}_{2} \mathrm{O}_{3}$ matrix. The fluorescence of AIN713 may be arising from fluorescent impurities and/or the polymer itself.

We also could not observe emission peaks for AIN821 even though the fluorescence maximum of AIN821 is relatively weak. We explain this by noting that the long wavelength wings have significant intensities (relative to the intensity of the emission signals) in the $650 \mathrm{~nm}$ region (see Figure 2-7). The excitation wavelength is $647.1 \mathrm{~nm}$ and so the emission spectra are observed in the region of $690 \mathrm{~nm}-700 \mathrm{~nm}$. However we could not collect

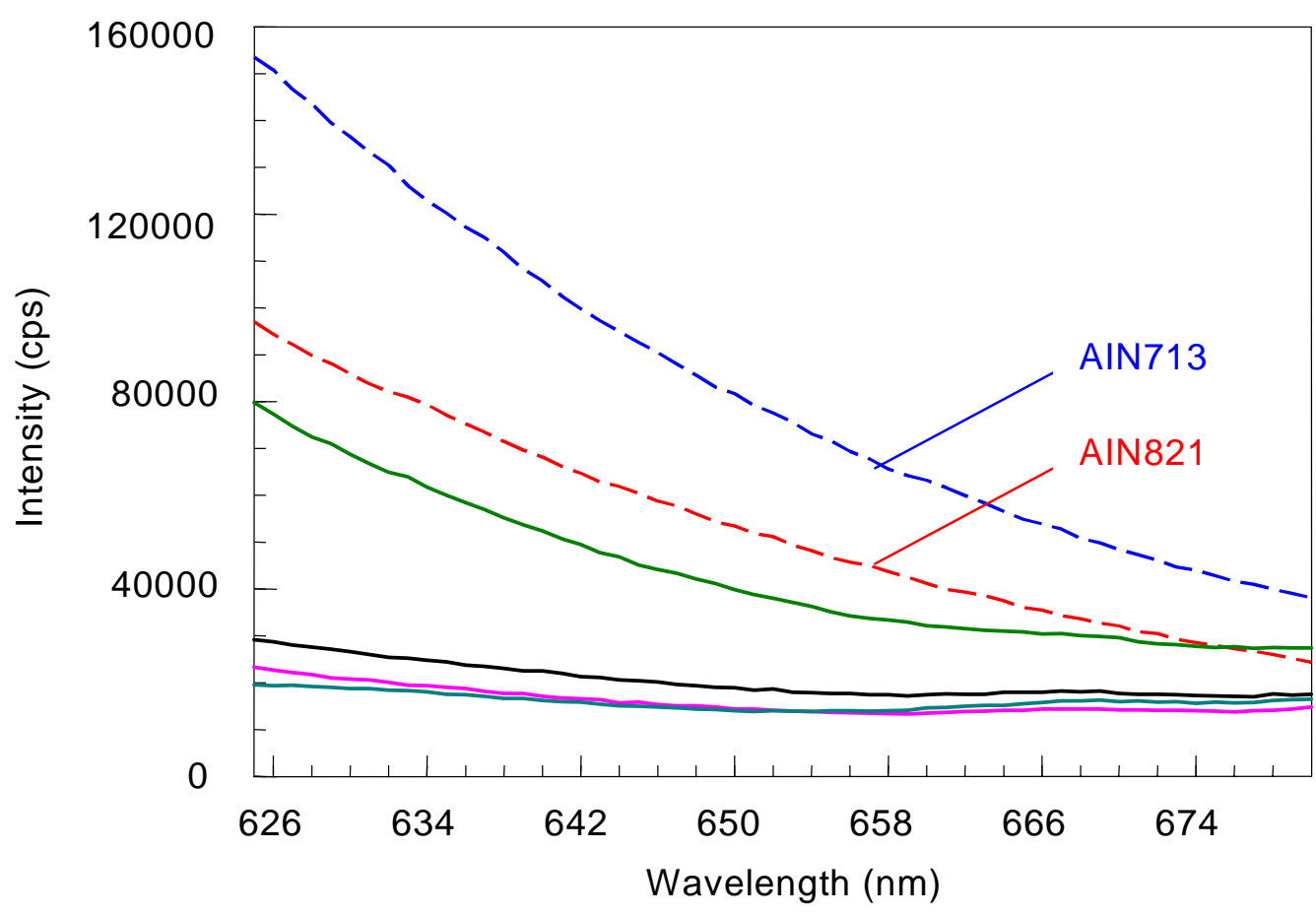

Figure 2-7. Fluorescence spectra of various polyacids in $650 \mathrm{~nm}$ region 
the fluorescence spectra of AIN821 and AIN713 in this range due to interference from the excitation lamp.

We collected emission spectra of AIN713 and AIN821 polyacids before and after purification and compared them to AIM811 polyacid as a reference. The representative emission spectra are shown in Figure 2-8 and Figure 2-9. We observed strong fluorescence in the emission spectra of both AIN713 and AIN821 before and after purification, even though the fluorescence intensity of polyacids after purification is lower. We conclude that the fluorescence observed in AIN713 and AIN821 is due to the inherent fluorescence of the polymers themselves.

Therefore the emission technique may not be suitable for all samples. Those samples with strong fluorescence in the $650 \mathrm{~nm}$ region cannot be studied using our method. 


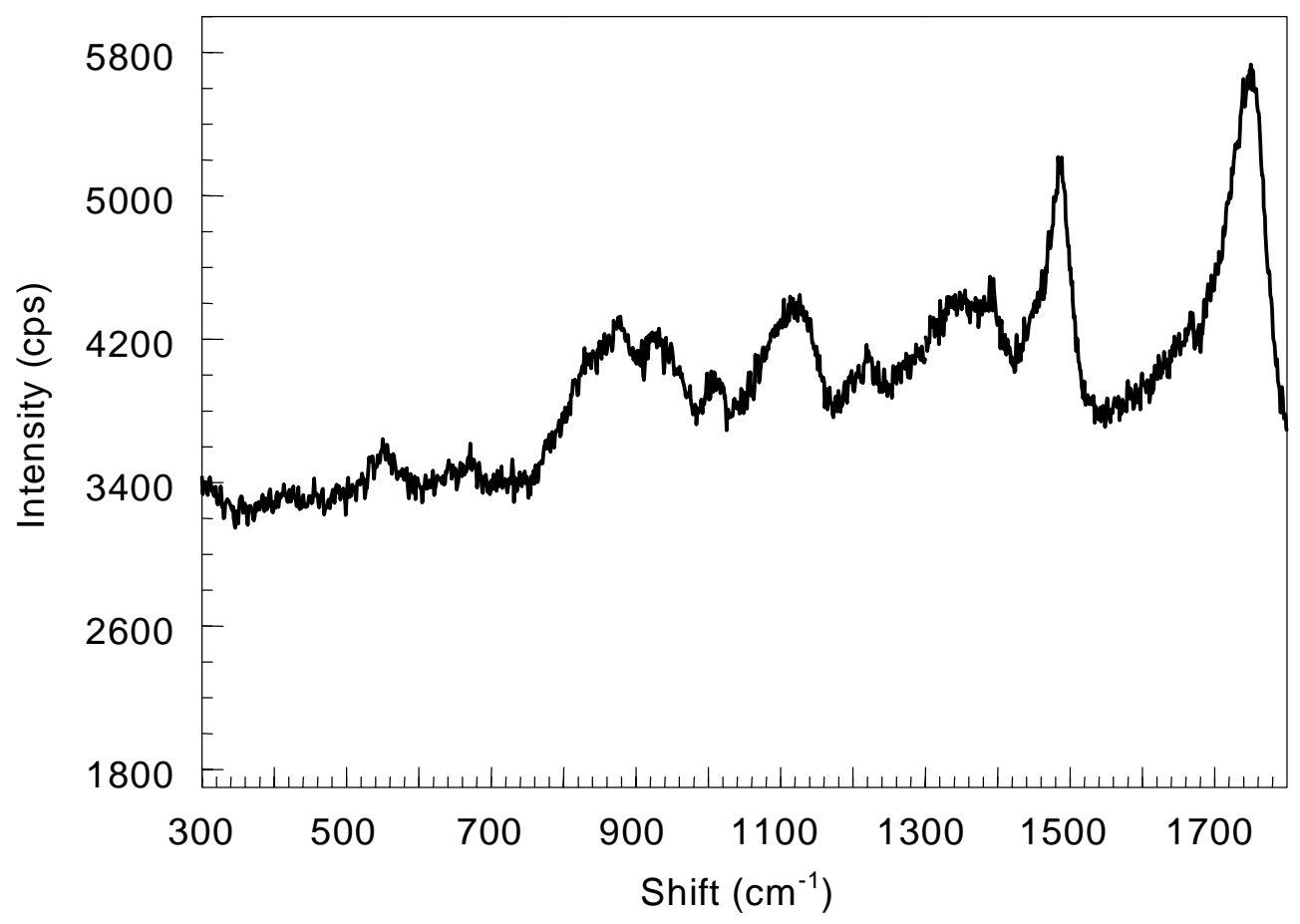

Figure 2-8. Emission spectrum of neat polyacid AIM811. Reference is to the excitation frequency $\left(15,453.56 \mathrm{~cm}^{-1}\right)$ at $0.0 \mathrm{~cm}^{-1}$.

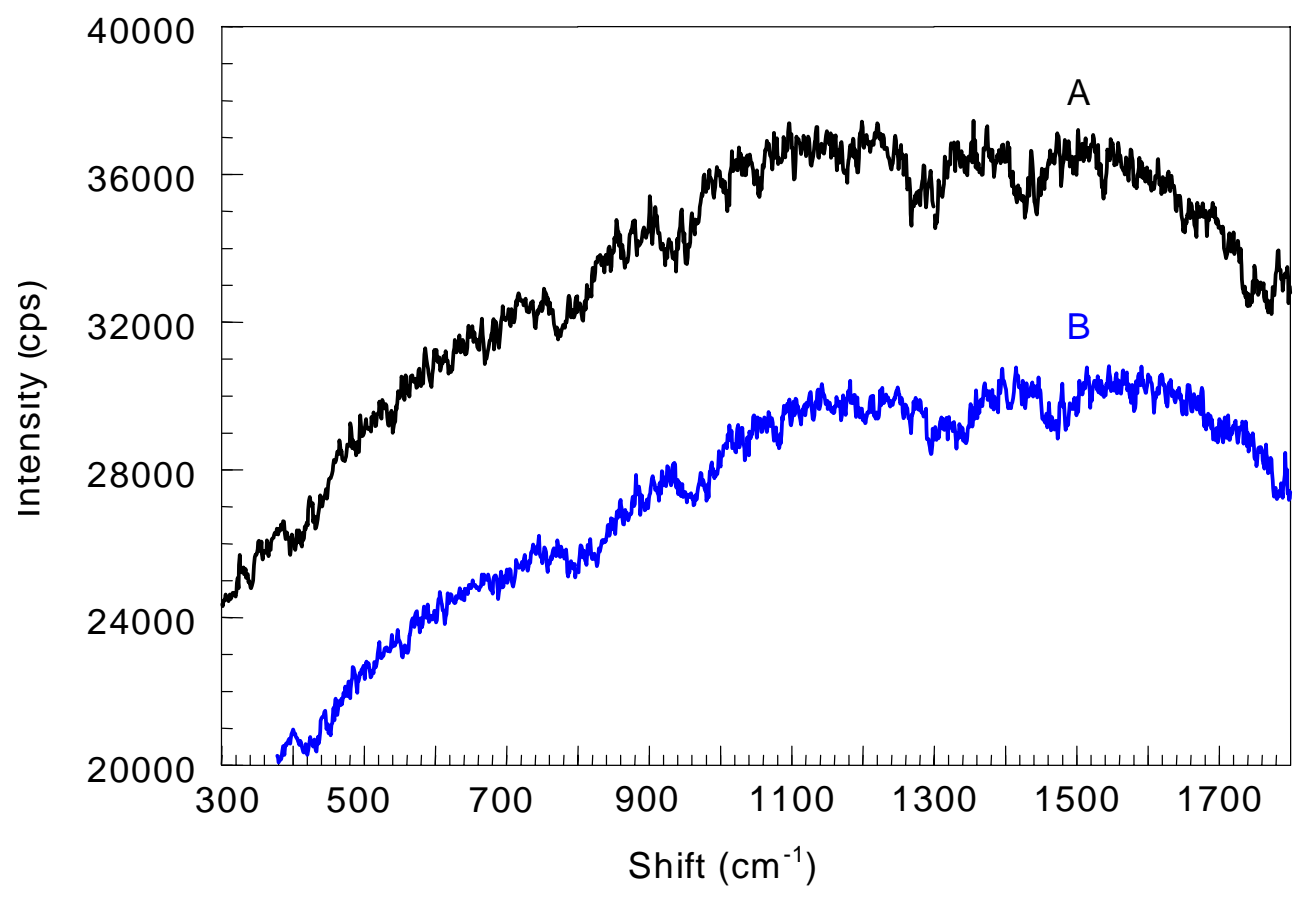

Figure 2-9. Emission spectrum of neat polyacid AIN821 before (A) and after (B) purification. Reference is to the excitation frequency $\left(15,453.56 \mathrm{~cm}^{-1}\right)$ at $0.0 \mathrm{~cm}^{-1}$. 


\subsection{CONCLUSION}

In this study, emission spectroscopy has been used to monitor different dental cement setting reactions. Compared to the methods Crisp and Wilson ${ }^{[10]}$ used, our method is less time consuming and labor intensive, and does not require destruction of the dental samples.

We applied a spectroscopic method based on comparison of integrated intensities of emission bands in the spectra of dental cements. It showed that F2 C has the fastest (shortest time of completion of setting reaction) and AMN713 has the slowest (longest time) initial setting reaction. It was also shown that AIM811 has the highest but F2 C, AMN731, and AMN713 have approximately the same, but lower $\mathrm{Al}_{2} \mathrm{O}_{3}$ percent than $\mathrm{AIM} 811$ at the completion of setting reaction.

We concluded that in the decomposition of glass powder, the polyacid with a higher concentration of $\mathrm{H}^{+}$ions (lower $\mathrm{pH}$ value), such as $\mathrm{F} 2 \mathrm{C}$, has a greater ability to extract metal ions from the calcium fluoro-alumino-silicate glass ionomers than AIM811 modified polyacid because of the different dissociation of $-\mathrm{COOH}$ groups and availability of $\mathrm{H}^{+}$ions due to their different structures. 
NVP modified polyacids have abilities to extract $\mathrm{Al}^{3+}$ ions from glass ionomer similar to $\mathrm{F} 2 \mathrm{C}$ polyacid, but greater abilities than AIM811 modified polyacid, because water soluble NVP terpolymers have a high concentration of $-\mathrm{COOH}$ groups. These terpolymers have potential in the formulation of glass-ionomer cements, which has been confirmed by previous studies. ${ }^{[11,12]}$ It has been experimentally proven that NVP modified glass-ionomer cements greatly improve the physical properties and the working property, ${ }^{[12]}$ due to the water retention characteristics of NVP due to its bulky pyrrolidone rings, in which the amide bonds are very good water sorption sites. ${ }^{[8,9]}$ As previously mentioned, water, which acts as a reaction medium, plays an important role in the setting reaction. ${ }^{[13]}$ However, excessive water in the system may result in a weak and slow-setting cement. $^{[13,14]}$ Therefore this NVP modified polyacid with water retention prolongs the working time and also may require less water or avoid unnecessary water added into the system, thus increasing the strength of the cement. $^{[12]}$

In addition, due to the fluorescence of some polymers, some of the samples may not be suitable to be studied using our emission spectroscopic method. Removal or avoiding the fluorescence interference of some samples is where our future work should focus. 


\section{REFERENCES}

1. E. C. Kao, B. M. Culbertson, and D. Xie, Dent. Mater., 12, 44-51, 1996

2. M. D. Lumb, Luminescence Spectroscopy, Acacemic Press, London, $9-13,1978$

3. Z. Ouyang, Glass Ionomer Cements: Understanding the Effects of Polyacid Substitution and Light Induced Polymerization, M.S. Thesis, West Virginia University, 1997

4. Z. Ouyang, S. K. Sneckenberger, E. C. Kao, B. M. Culbertson, and P. W. Jagodzinski, Applied Spectroscopy, 53(3), 297-301, 1999

5. D. O. Hummel, Polymer Spectroscopy, Verlag Chemie GmbH, Weinheim/Bergstv, Germany, 159, 1974

6. D. P. Strommen and K. Nakamoto, Laboratory Raman Spectroscopy, Wiley Interscience, New York, 64, 1984

7. D. A. Skoog, D. M. West, and F. J. Holler, Fundamentals of Analytical Chemistry, Saunders College Publishing, New York, NY, 26-33, 1988

8. E. A. Bekturov and Z. Kh. Bakauova, Synthetic Water-Soluble Polymers in Solution, Huethig \& Wepf, Basel, 1986

9. M. Dole and I. L. Faller, J. Am. Chem. Soc., 72, 414-419, 1950

10. S. Crisp and A. D. Wilson, J. Dent. Res., 53, 1408-1413, 1974 
11. D. Xie and B. M. Culbertson, J. Dent. Res., 75, 298, 1996

12. D. Xie, B. M. Culbertson, and G. Wang, J.M.S.-Pure Appl. Chem., A35(4), 547-561, 1998

13. A. D. Wilson and J. W. McLean, Glass-Ionomer Cement, Quintessence Publishing Co., Inc., Chicago, IL, 1988

14. S. Akahane, et al., Dental Glass Ionomer Cement Compositions, U.S. patent: 5,063,257, Nov.5, 1991 


\section{CHAPTER 3}

\section{SPECTROSCOPIC INVESTIGATIONS OF RESIN MODIFIED GLASS-IONOMER DENTAL CEMENTS}

\subsection{INTRODUCTION}

As we know, the setting of the conventional glass-ionomer cement is an acid-base neutralizing reaction of a calcium fluoro-alumino-silicate glass and an aqueous solution of polyacid. ${ }^{[1]}$ However, the practical disadvantages of the conventional cement are short working times and long set times. ${ }^{[2]}$ In addition, the cement is affected by hydration and also dehydration, since upon coming into contact with water at the early stages of setting reaction, the hardened paste clouds on its surface and is embrittled resulting in reduced strength. ${ }^{[2,3]}$

To address this issue, techniques and materials for light-induced polymerization of glass-ionomer cements were developed. ${ }^{[3]}$ These cements are commonly based on resin modified (RM) glass-ionomer cements. RM glass-ionomer cements are cements in which resin is incorporated into the 
polyacid-ion leachable conventional glass system which significantly improves water sensitivity, handling characteristics, and physical properties. ${ }^{[4]}$

The composition of the RM glass-ionomer cement (specifically Fuji II resin modified cement F2 LC used in this study) is similar to that of the conventional cement, i.e. it contains a calcium fluoro-alumino-silicate glass powder and an aqueous solution of a polymer of a carboxylic acid. In addition, there are 5 to 100 parts by weight of a polymerizable unsaturated organic compound having $\mathrm{CH}_{2}=\mathrm{C}(\mathrm{R} 1)-\mathrm{COO}-$ group(s) where $\mathrm{R} 1=\mathrm{H}$ or $\mathrm{CH}_{3}$ and 0.01 to 20 parts by weight of a surface active agent included in the RM polyacid liquid. Also 0.01 to 5 parts by weight of a polymerization catalyst and 0.01 to 5 parts by weight of a reducing agent are added to the RM glass ionomer (detailed information about the concentration of commercially available RM glass-ionomer cements is unknown). ${ }^{[3]}$ The polymerizable unsaturated organic compound containing $\mathrm{CH}_{2}=\mathrm{C}(\mathrm{R} 1)-\mathrm{COO}-$ group(s) may be an ester of acrylic or methacrylic acid (e.g. methyl acrylate, methyl methacrylate, etc.), which undergoes no reaction with the calcium fluoroalumino-silicate glass powder, but does react with the polyacid. The organic compound is also reactive with the surface of the silica gel after the cement is set. The surface active agent (such as a sorbitan fatty acid ester, a glycerin 
fatty acid ester, etc.) is used to ensure the polymerizable unsaturated organic compound uniformly mixes and emulsifies with the water in the reaction mixture. The polymerization catalysts may be carbonyl photopolymerization initiators, such as adjacent polyketones, $\alpha$-carbonyl alcohols, etc., and their combinations. The reducing agent, which is used in combination with the photopolymerization initiators to make the curing sharper and quicker, may be an amine, for example, dimethylaminoethyl methacrylate or n-butylamine. ${ }^{[3]}$

Another RM glass-ionomer cement (Vitremer 3M) primarily comprises of reactive glass powder, polyacrylic acid, and photopolymerizable cosolvent. ${ }^{[5]}$ However, the polyacid in Vitremer is grafted with unsaturated methacrylates $\left(-\mathrm{R}-\mathrm{C}\left(\mathrm{CH}_{3}\right)=\mathrm{CH}_{2}\right.$, where the terminal group could be $-\mathrm{OH}$, $-\mathrm{NCO}$, etc.). ${ }^{[6]}$ Since the modified polyacid contains unsaturated groups, it will copolymerize with the cosolvent monomer, thus the polymer network will be chemically linked to polysalts matrix, which avoids phase separation. Therefore the strength of this new $\mathrm{RM}$ cement is greatly increased.

Due to their special components, RM glass-ionomer cements have many advantages: 1) When the calcium fluoro-alumino-silicate glass powder is coated with a polymerizable unsaturated organic compound, the physical 
properties of the resulting cement are greatly improved. 2) The setting can occur initially due to the neutralizing reaction of the glass ionomer with the polyacid concurrent with the polymerizing reaction of the polymerizable component. Therefore, in the early stages, the setting reaction can proceed rapidly to form a glass-ionomer cement that is much less water sensitive in the RM mixture than in a conventional mixture. ${ }^{[3]}$ It has been shown that the cement is almost independent of water content after 20 seconds of light irradiation. ${ }^{[7]}$

In our study, we used emission spectroscopy to compare the differences in the polysalt formation of RM glass-ionomer cements with and without light irradiation. We found that the setting reactions due to the polysalt formation are affected by the light-induced polymerization process for these samples.

\subsection{EXPERIMENTAL}

\section{Materials and Methods}

Two commercially available RM glass-ionomer dental cements F2 LC

(GC Corporation, Tokyo, Japan) and Vitremer (3M Dental Products, St. Paul, MN) were used in the study. One experimental RM polyacid 
poly(AA-co-IA-co-NVP) with a molar ratio of 7:1:3 and grafted with $10 \%$ 2-isocyanatoethylmethacrylate (AIN713-IEM), received from Prof. Elizabeth C. Kao in the School of Dentistry at West Virginia University and Prof. Bill M. Culbertson in the School of Dentistry at Ohio State University was also included.

The commercial RM glass-ionomer (F2 LC and Vitremer) powder and the liquid were mixed very quickly as previously described and loaded into a standard capillary tube within 30 seconds. This sample must be manipulated much faster than the conventional cements because the commercially available RM polyacid liquid is highly viscous and so the working time is very short. Water cannot be used to dilute the liquid since the RM glass powder surface is coated with an organic compound which makes it insoluble in water. The ratio of glass powder : liquid used in this experimental study was $1: 3$ by weight.

The experimental RM polyacid AIN713-IEM solid was dissolved in water and hydroxyethylmethacrylate (HEMA) with a weight ratio RM polyacid : water : HEMA of $55: 30: 15 .{ }^{[8]} \mathrm{F} 2$ LC glass powder was rapidly mixed with the experimental polyacid solution in a glass powder : polyacid solution weight ratio of $1: 3$ and loaded into a standard capillary tube within 30 seconds. 
We collected and analyzed emission signals of the cement without light irradiation as described in the previous chapter. The cement with light irradiation was exposed to a ELIPAR VISIO (Model D-8031; ESPE GmbH, Seefeld, Germany) visible blue light for about 30 seconds after mixing. The wavelength of the blue light is $470 \mathrm{~nm}$. The emission spectra were collected and analyzed 4 times to generate the percent of $\mathrm{Al}_{2} \mathrm{O}_{3}$ as a function of time with the procedures described in the previous chapter. We also collected the fluorescence spectra of F2 LC and AIN713-IEM polyacid liquids with the procedures described previously.

\subsection{RESULTS AND DISCUSSION}

\section{Spectroscopic Investigations of Resin Modified Dental Cements}

The polyacid used in this part of study was F2 LC which is poly(AA-co-IA). Its structure is presented in Figure 1-2. However, 5 to 100 parts by weight of polymerizable unsaturated organic compounds are contained in the liquid. ${ }^{[3]}$ The glass-ionomer powder used was F2 LC. The components of F2 LC glass ionomer are almost identical to those of F2 C glass ionomer (see Table 1-1.ii), except there are 0.01 to 5 parts by weight of light polymerizing catalysts in F2 LC glass. ${ }^{[3]}$ 
We collected and analyzed data at different reaction times as previously described and plotted the $\mathrm{Al}_{2} \mathrm{O}_{3}$ percentage vs. the reaction time. The results for the F2 LC glass-ionomer cement with and without lightinduced polymerization are shown in Figure 3-1 (see Appendix B for standard errors). We found that the setting reaction of F2 LC RM dental cement was completed at different times and percentages. For the cement with light-induced polymerization, the setting was completed quickly and was almost finished in about 15 minutes (i.e. the completion of the polysalt formation is rapid). However, the percent of $\mathrm{Al}_{2} \mathrm{O}_{3}$ remaining after completion of the setting reaction was about $62 \%$. The cement without lightinduced polymerization proceeded relatively slowly and needed about 20 minutes to set. In other words, the completion of the polysalt formation is slow. However, the $\mathrm{Al}_{2} \mathrm{O}_{3}$ percent remaining after completion of the setting reaction was a lower value of $37 \%$.

In this experimental study, the concentration of F2 LC polyacid liquid used (powder : liquid $=1: 3$ by weight) was higher than that of F2 C polyacid solution used. Therefore the polysalt percentages for F2 LC dental cement are expected to be higher than those for F2 C cement. However, we found F2 LC had more $\mathrm{Al}_{2} \mathrm{O}_{3}$ remaining (less polysalts formed). This could be explained by the low concentration of the glass powder which has less 
chance to react with polyacid and lack of water ${ }^{[3]}$ (necessary reaction medium to transport ions) which leads to some of the metal ions being unleachable, thus the initial acid-base reaction is slowed down. ${ }^{[6]}$

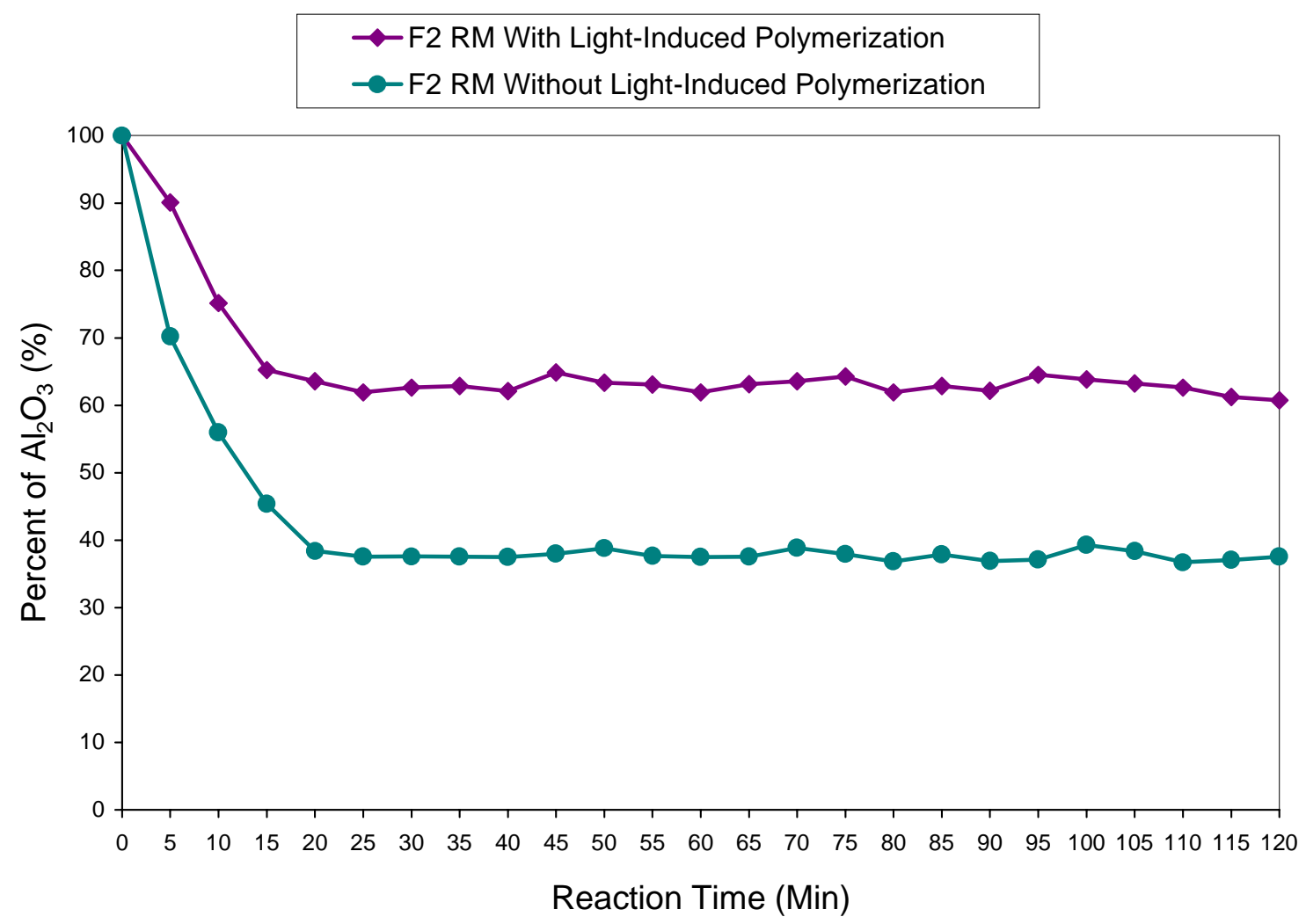

Figure 3-1. Time dependence of $\mathrm{Al}_{2} \mathrm{O}_{3}$ percent in $\mathrm{F} 2 \mathrm{LC}$ glass-ionomer dental cement with and without light-induced polymerization

We can explain the different times for completion of the setting reaction and the percentages of polysalts formed in the presence and absence of light. We know that 5 to 100 parts by weight of polymerizable unsaturated organic compounds containing $\mathrm{CH}_{2}=\mathrm{C}(\mathrm{R} 1)$-COO- group(s) are 
added in F2 LC liquid and 0.01 to 5 parts by weight of light polymerization catalysts are added in F2 LC glass for the light-induced polymerization. ${ }^{[3]}$ When the cement is light cured, the polymerization occurs and the polymer network forms quickly. This confines the metal ions in a small area due to the network. The high concentration of the metal ions in the local areas leads to the fast polysalt formation. However, since the metal ions are not accessible due to the polymer network and cannot be extracted by $\mathrm{H}^{+}$ions, the percent completion of setting reaction is decreased (i.e. a higher percent of $\mathrm{Al}_{2} \mathrm{O}_{3}$ remaining). After the formation of the polymer network in the $\mathrm{RM}$ glass-ionomer cements with light-induced polymerization, the polymer network can be connected with the polysalt network and the silicate network, thus greatly improving the physical properties. In the RM system, there is less water content which slows down the initial acid-base reaction due to the decreased dissociation of polyacid to $\mathrm{H}^{+}$and $-\mathrm{COO}^{-}$ions. Therefore the initial set of RM cements is the result of polymerization, but not the result of the conventional acid-base reaction. The acid-base reaction only occurs to harden and strengthen the polymer network after it is formed. ${ }^{[6]}$ In the absence of light, polysalt formation occurs more slowly, thus allowing the migration of $\mathrm{H}^{+}$ions and extraction of metal ions to occur over a longer time period. This leads to an increased concentrations of 
polysalts and a lower percent $\mathrm{Al}_{2} \mathrm{O}_{3}$ remaining.

In a previous study, Ouyang ${ }^{[9]}$ used FTIR spectroscopic techniques to monitor the reaction of a light-cured dental cement and found that with light irradiation, the $\mathrm{C}=\mathrm{C}$ double bonds in the polymerizable monomers are broken and the monomers polymerize to form a network. Based on this result, a mechanism for the light-induced polymerization and the surface reaction between the silica gel and the monomers was proposed. This is shown in Figure 3-2. Once the silica gel forms in the cement, a hydrogen bond is formed between one $-\mathrm{OH}$ group in the silica gel and the carbonyl $(-\mathrm{C}=\mathrm{O})$ group in the monomer. Then the $-\mathrm{OH}$ group reacts with the carbonyl carbon to form a tetrahedral structure, followed by the release of $\mathrm{CH}_{3} \mathrm{OH}$. Through light-induced polymerization, the $\mathrm{C}=\mathrm{C}$ bond is broken and the polymer network forms making the cement tough and resistant to water prior the formation of the polysalt network and the silicate network. Finally the polymer network and the silicate network are connected by the $-\mathrm{COO}-$ $\mathrm{Si}-$ groups, which greatly enhances the strength of the cement.

We did not observe emission signals for Vitremer resin glass-ionomer cement and its glass powder (see Figure 3-3). Compared to the compositions of G-200 and Fuji II glass ionomers (see Table 1-1), we noticed that in Vitremer resin glass ionomer, there is very low percent of $\mathrm{Al}_{2} \mathrm{O}_{3}$ (only 

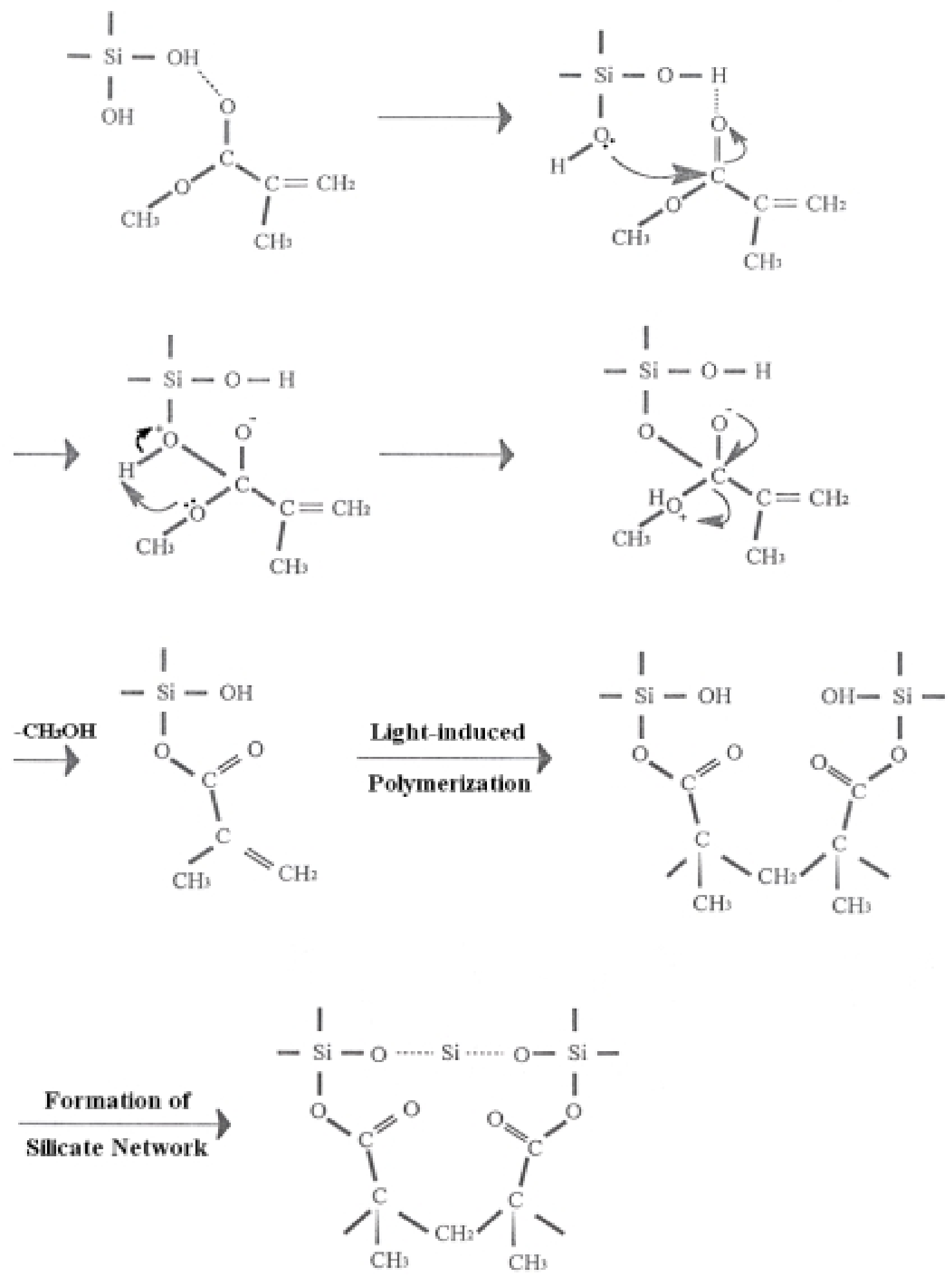

Figure 3-2. Mechanism of light-induced polymerization and surface reaction. ${ }^{[9]}$ 


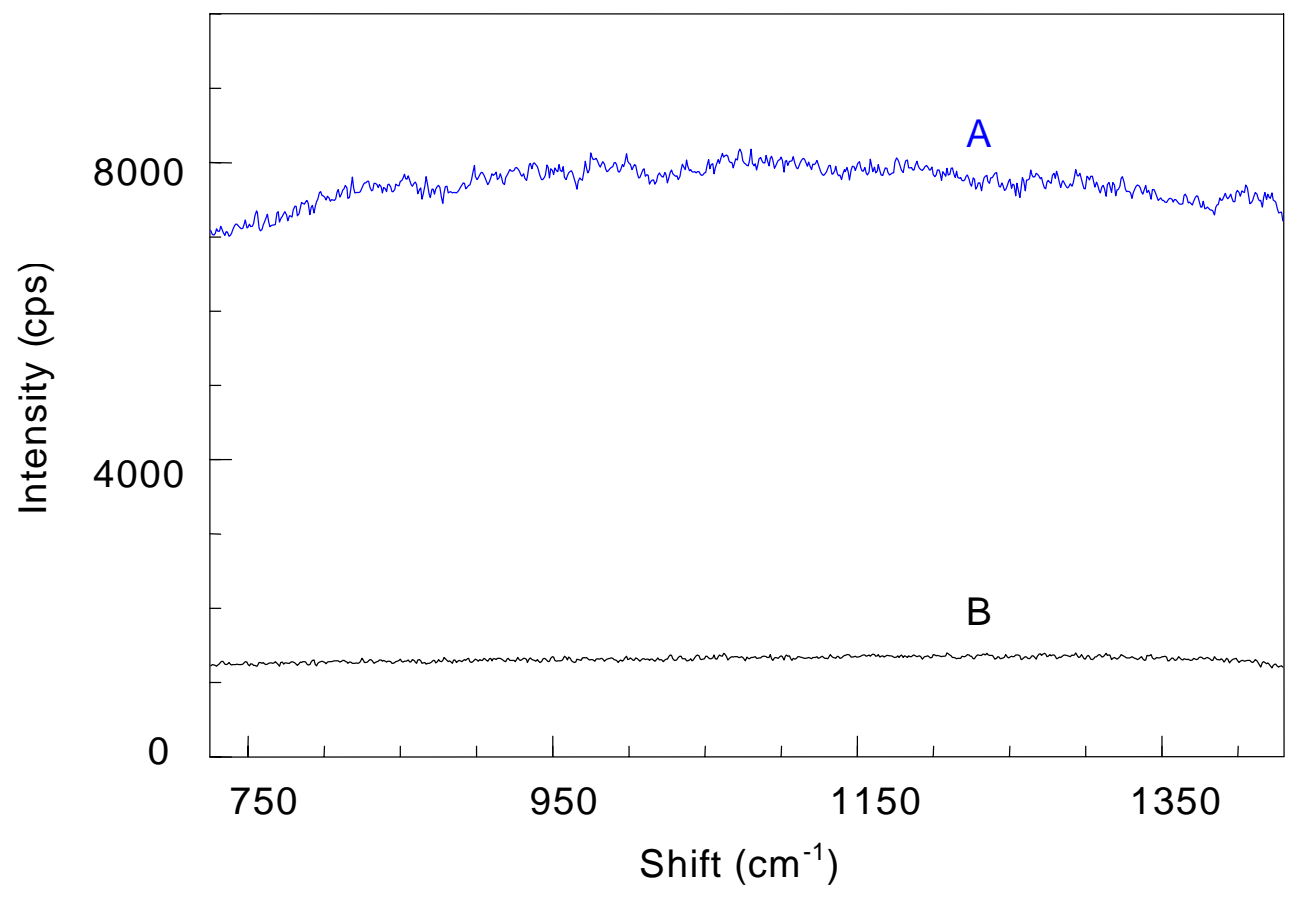

Figure 3-3. Emission spectra of Vitremer RM glass-ionomer dental cement (A) and its glass powder (B). Reference is to the excitation frequency $\left(15,453.56 \mathrm{~cm}^{-1}\right)$ at $0.0 \mathrm{~cm}^{-1}$.

$0.80 \%$ ), even though the percent of $\mathrm{Al}^{3+}$ is high (see Table 3-1). ${ }^{[6]}$ Our emission signals are due to $\mathrm{Cr}^{3+}$ ions in $\mathrm{Al}_{2} \mathrm{O}_{3}$ matrix (which is called ruby). The emission bands are due to the transitions involving $\mathrm{Cr}^{3+}$ ions held in $\mathrm{Al}_{2} \mathrm{O}_{3}$ matrix. ${ }^{[10]}$ Therefore a high percent of $\mathrm{Al}_{2} \mathrm{O}_{3}$ with some $\mathrm{Cr}^{3+}$ ions is required in the glass ionomer for a strong emission signal. 


\begin{tabular}{|c|c|}
\hline Component & Composition (\%) \\
\hline $\mathrm{Al}_{2} \mathrm{O}_{3}$ & 0.80 \\
\hline $\mathrm{SiO}_{2}$ & 26.84 \\
\hline $\mathrm{AlF}_{3}$ & 20.66 \\
\hline $\mathrm{P}_{2} \mathrm{O}_{5}$ & 0.94 \\
\hline $\mathrm{NH}_{4} \mathrm{~F}$ & 3.32 \\
\hline $\mathrm{Na}_{3} \mathrm{AlF}$ & 10.65 \\
\hline $\mathrm{ZnO}$ & 20.66 \\
\hline $\mathrm{MgO}$ & 2.12 \\
\hline $\mathrm{SrO}$ & 12.55 \\
\hline
\end{tabular}

Table 3-1. Compositions of Vitremer resin glass ionomer ${ }^{[6]}$

\section{Fluorescence of Resin Modified Polyacid}

The fluorescence spectra of F2 LC and AIN713-IEM RM polyacids are shown in Figure 3-4 and Figure 3-5. As described in Chapter 2, we found even stronger intensity of AIN713-IEM than that of AIN821 in both $420 \mathrm{~nm}$ and $650 \mathrm{~nm}$ regions. We were not able to observe emission signals for AIN713-IEM RM cement due to the fluorescence interference. 


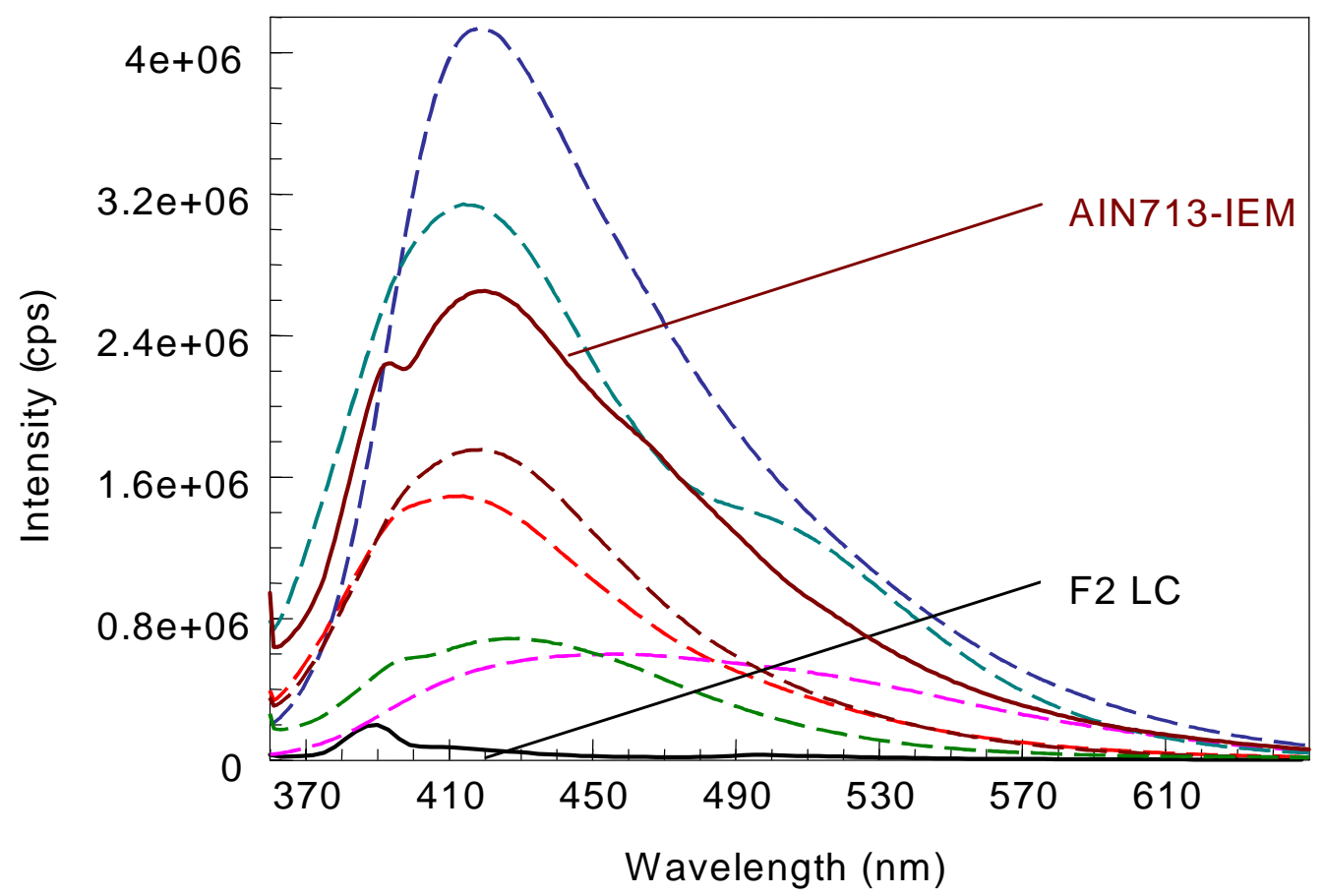

Figure 3-4. Fluorescence spectra of F2 LC and AIN713-IEM RM polyacids (dotted lines are fluorescence spectra of modified polyacids)

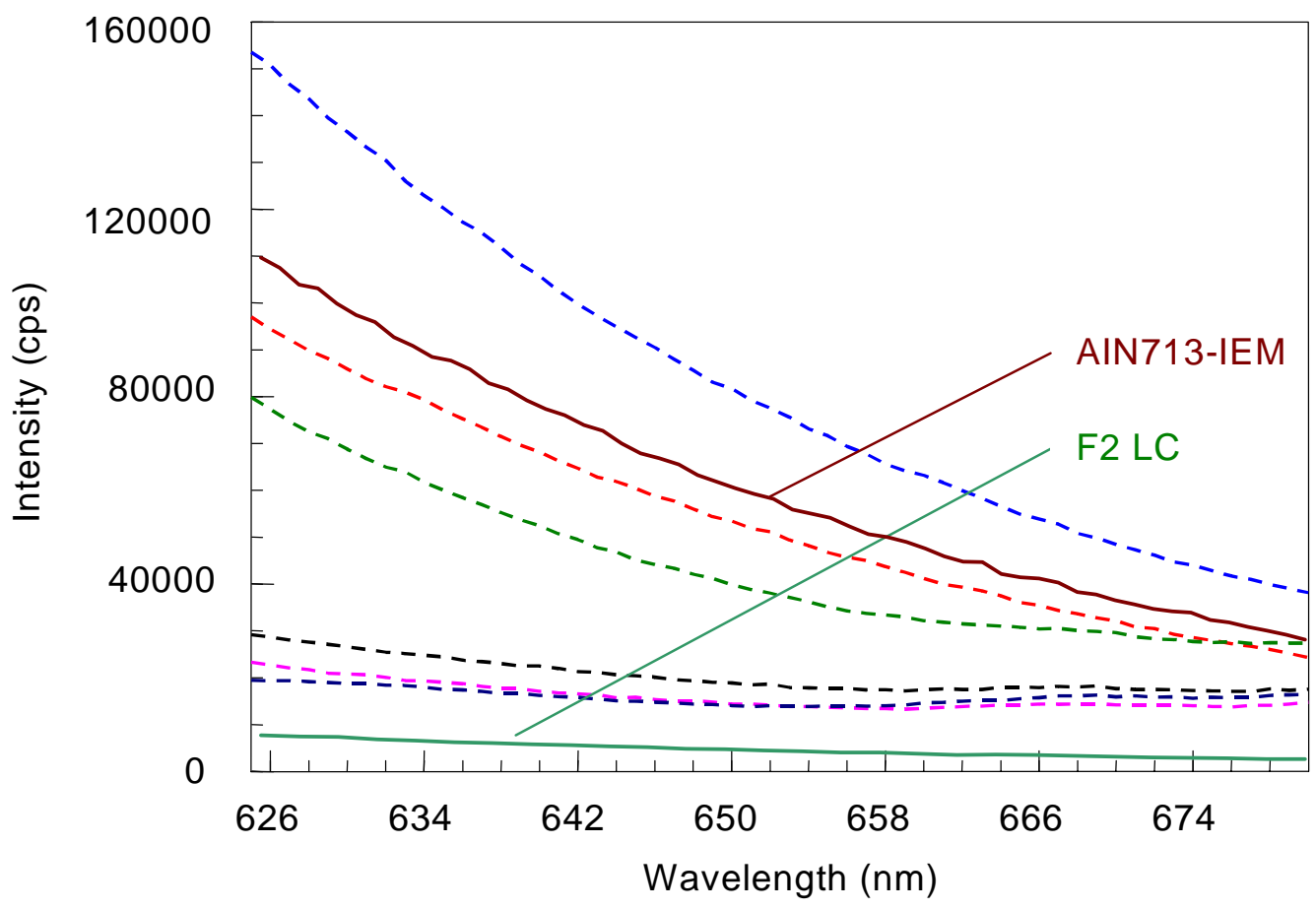

Figure 3-5. Fluorescence spectra of F2 LC and AIN713-IEM RM polyacids in $650 \mathrm{~nm}$ region (dotted lines are fluorescence spectra of modified polyacids) 


\subsection{CONCLUSION}

Emission spectroscopy has been used to study the properties of an RM glass-ionomer dental cement. In the RM glass-ionomer dental cement, a lower percentage of polysalts is formed and a slower initial polysalt formation results in a longer working time than the conventional cement. However, the polysalt formation of the RM cement with light-induced polymerization is completed more rapidly than that without light-induced polymerization. Fewer polysalts are formed because of the polymer network formation and the locally high concentration of metal ions, some of which may not be accessible due to the confined network. Light polymerizable compounds are incorporated to make the cement set faster and harder. When the polymer network forms, it enhances the polysalt network and the silicate network and improves the physical properties of the dental cement. ${ }^{[6,9]}$ The RM cement diminishes the importance of the acid-base reaction, since the light-induced polymerization occurs and dominates the initial setting reaction. ${ }^{[6]}$

In our emission spectroscopic method, the limitation is that $\mathrm{Cr}^{3+}$ ions in $\mathrm{Al}_{2} \mathrm{O}_{3}$ matrix is the only source that could be tracked experimentally and that $\mathrm{Al}^{3+}$ ions can not be used as the tracer. ${ }^{[10]}$ This requires a high 
percentage of $\mathrm{Al}_{2} \mathrm{O}_{3}$ with some $\mathrm{Cr}^{3+}$ ions in the glass ionomer (simply a high percentage of $\mathrm{Al}^{3+}$ ions is not sufficient). Therefore the study of those glass ionomers with low percents of $\mathrm{Al}_{2} \mathrm{O}_{3}$ using our method is not suitable.

Future work will involve the study of other RM glass-ionomer dental cements comparing them to the commercially available RM dental cements. 


\section{REFERENCES}

1. A. D. Wilson and J. W. McLean, Glass-Ionomer Cement, Quintessence Publishing Co., Inc., Chicago, IL, 1988

2. Vrijhoef and Mitra, Present and Future of Glass Ionomers, St. Paul

3. S. Akahane, et al., Dental Glass Ionomer Cement Compositions, U.S. patent: 5,063,257, Nov.5, 1991

4. A. Kakaboura, G. Eliades, and G. Palaghias, Dent. Mater., 12, 173-178, 1996

5. S. B. Mitra, Photocurable Ionomer Cement Systems, U.S. patent: 5,130,347, Jul.14, 1992

6. A. D. Wilson, Int. J. Prosthodont, 3, 425-429, 1990

7. S. Katsuyama, T. Ishikawa, and B. Fujii, Glass Ionomer Dental Cement, Ishiyaku EuroAmerica, Inc. Publishers, St. Louis, MO, 1993

8. D. Xie, B. M. Culbertson, and W. M. Johnston, J.M.S.-Pure Appl. Chem, A35(10), 1631-1650, 1998

9. Z. Ouyang, Glass Ionomer Cements: Understanding the Effects of Polyacid Substitution and Light Induced Polymerization, M.S. Thesis, West Virginia University, 1997 
10. M. D. Lumb, Luminescence Spectroscopy, Acacemic Press, London, 9-13, 1978 


\section{CHAPTER 4}

\section{CONCLUSIONS}

Emission spectroscopy has been used to study glass-ionomer dental cements. Through analyzing the integrated peak intensities of spectroscopic signals due to chromium $\left(\mathrm{Cr}^{3+}\right)$ ions in an aluminium oxide $\left(\mathrm{Al}_{2} \mathrm{O}_{3}\right)$ matrix, the setting reactions of modified glass-ionomer dental cements were monitored. It was demonstrated that modified polyacids with different structures have different potentials to release hydrogen $\left(\mathrm{H}^{+}\right)$ions. Those with higher concentrations of $\mathrm{H}^{+}$ions (i.e. lower $\mathrm{pH}$ values) can more effectively extract metal ions from the calcium fluoro-alumino-silicate glass ionomers and thus improve the formation of polysalts leading to stronger cements.

During the early stages of the reaction, the glass ionomer is decomposed, carboxylate $\left(-\mathrm{COO}^{-}\right)$ions and hydrogen $\left(\mathrm{H}^{+}\right)$ions are formed, metal ions are extracted by $\mathrm{H}^{+}$ions and released from the glass, and silica gel starts to form. In the later stages of the reaction, networks such as polymer crosslinks, silica gel, and calcium and aluminium polysalts form and finally the dental paste hardens with silicate network reconstruction.

In the conventional glass-ionomer dental cements, two types of 
networks (the polysalts network and the silicate network) form rapidly and the setting reaction is almost completed within 20-60 minutes of reaction. The more polysalts formed, the better the physical properties of the cements. However, polysalt formation can be hindered because $-\mathrm{COOH}$ groups are ionized incompletely or sterically hindered and become inaccessible. In our study, higher concentrations of $\mathrm{H}^{+}$ions (i.e. lower $\mathrm{pH}$ values in the isolated polyacids) and/or water retention characteristics due to different polyacid structures leads to larger amounts of polysalt formation.

For the resin modified glass-ionomer cements, besides the polysalts network and silicate network, a polymer network is formed by light-induced polymerization. The initial domination of polymerizing reaction slows down the conventional acid-base reaction in the resin modified cement which allows for longer working times than that in the conventional cement. When polymerization occurs, the polymer network is formed resulting in locally high concentrations of metal ions which may be trapped and not be readily available to contribute to the further acid-base reaction. The result is that the polysalt formation is faster, but a lower concentration of polysalts is formed. The polymer network enhances the strength of the polysalt network and the silicate network, which makes the cements harder and improves the physical properties of the cements. 
In the study, we also investigated the fluorescence of some polyacid samples and found interference of the emission signals due to fluorescence. Attempts with two purification methods to remove fluorescent impurities indicated that some of the fluorescence may be intrinsic to the polymer components. Avoiding the fluorescence interference is where our future work should focus. In the future, we may try: 1) changing to another excitation wavelength; 2) using other purification methods to increase purification levels.

We also concluded that emission spectroscopic signals of the glass ionomer with low percent of $\mathrm{Al}_{2} \mathrm{O}_{3}$ composition could not be detected and that $\mathrm{Cr}^{3+}$ ions in $\mathrm{Al}_{2} \mathrm{O}_{3}$ matrix is the only tracer in our method. This is one of the limitations using our method.

Although emission spectroscopic method has many advantages, the future improvements are still necessary, which should focus on:

1) Better and more efficient ways to mix dental cement samples. We may try mixing equipment, such as triturator, instead of hand mixing;

2) Same ratios to mix RM glass-ionomer dental cements as conventional cements in order to obtain more comparable data; 
3) Lower optical power of laser and longer scan times to avoid photodecomposition and to increase reproducibility;

4) Better sample container and/or holder design in which highly viscous samples can be easily loaded;

5) Better sample scanning device which allows to scan samples by laser beam in multiple points or in an area and to obtain more representative data for the reaction of the whole sample. 


\section{APPENDICES}




\section{APPENDIX A}

\section{Standard Error Bars for Figure 2-5 \\ by Microsoft ${ }^{\circledR}$ Excel Program}

\section{Time Dependence of $\mathrm{Al}_{2} \mathrm{O}_{3}$ Percentage in F2 C Glass lonomer When Reacted With Various Polyacids Shown in Legend}

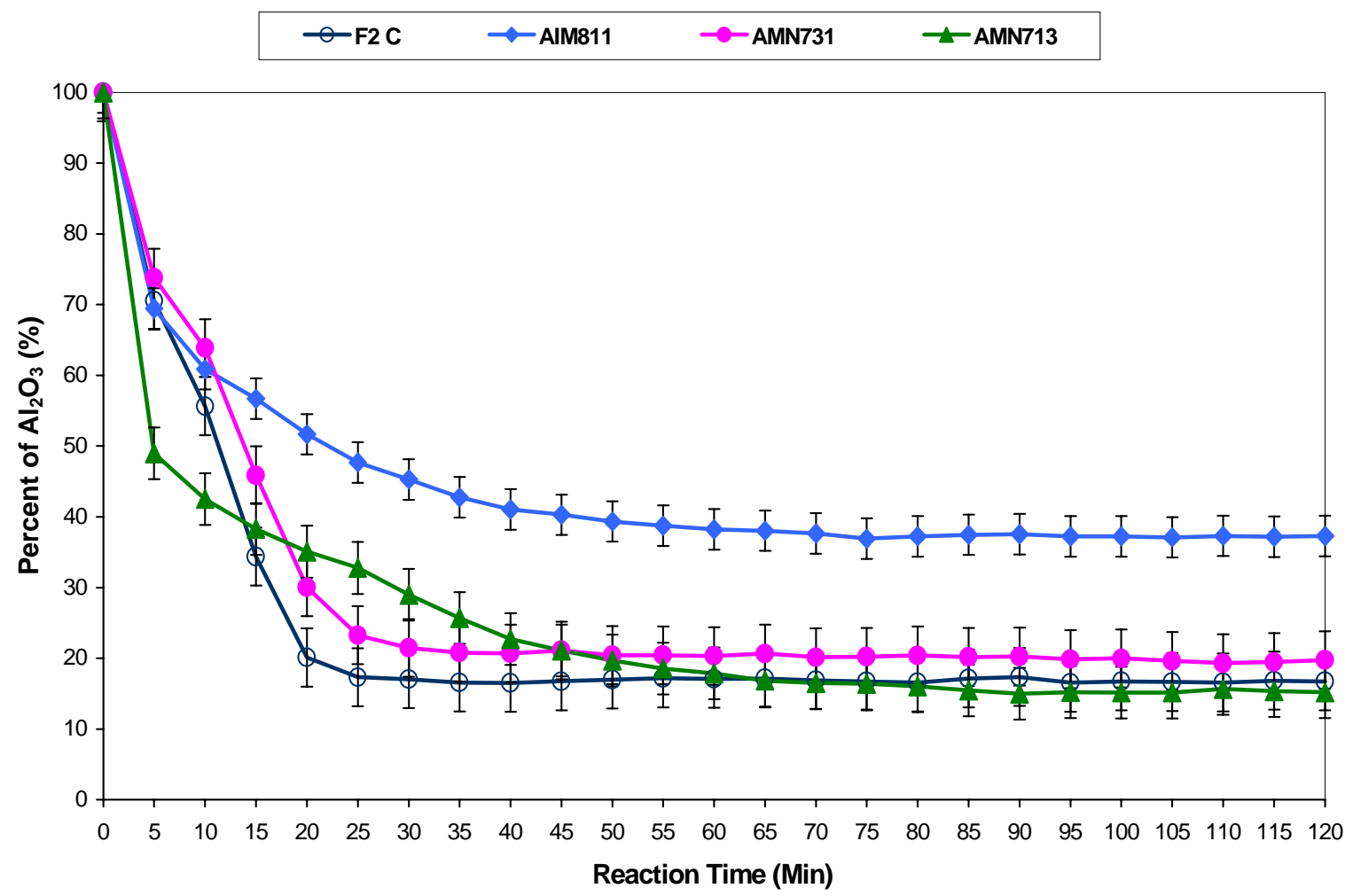




\section{APPENDIX B}

\section{Standard Error Bars for Figure 3-1 \\ by Microsoft ${ }^{\circledR}$ Excel Program}

Time Dependence of $\mathrm{Al}_{2} \mathrm{O}_{3}$ Percentage in F2 LC Glass-lonomer

Dental Cement With and Without Light-Induced Polymerization

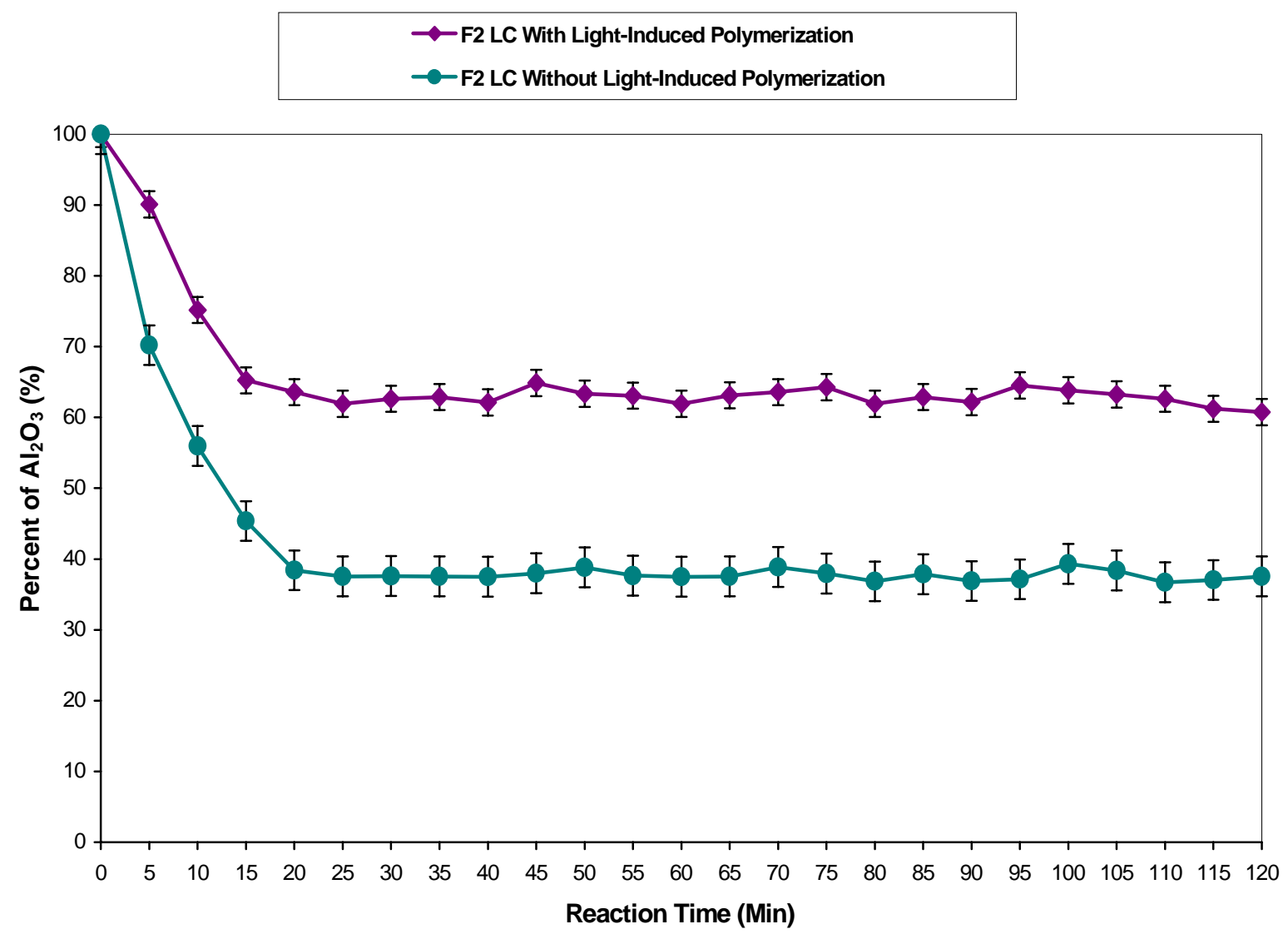




\section{APPENDIX C}

\section{Confidence Intervals* for Table 2-2 by Microsoft ${ }^{\circledR}$ Excel Program}

$\mathrm{pH}$ values of various polyacids

\begin{tabular}{|c|c|c|c|c|c|c|c|}
\hline & $x_{1}$ & $x_{2}$ & $x_{3}$ & $x$ & $s$ & $t s / N^{1 / 2}$ & $p H$ \\
\hline F2 C & 1.71 & 1.74 & 1.73 & 1.726667 & 0.015275 & 0.025753 & $1.73 \pm 0.02$ \\
\hline AMN731 & 1.87 & 1.89 & 1.88 & 1.880000 & 0.010000 & 0.016859 & $1.88 \pm 0.02$ \\
\hline AIM811 & 2.00 & 2.02 & 2.00 & 2.006667 & 0.011547 & 0.019467 & $2.01 \pm 0.02$ \\
\hline AMN713 & 2.97 & 3.00 & 2.98 & 2.983333 & 0.015275 & 0.025753 & $2.98 \pm 0.02$ \\
\hline
\end{tabular}

* Confidence level is $90 \%$ and degree of freedom is 2 . 